\title{
REGIMEN DE PROPIEDAD Y TRABAJO POR CUENTA PROPIA EN CUBA: DE 1959 A LA NUEVA CONSTITUCIÓN DE 2019*
}

\author{
Property regime and work for own account in Cuba: \\ from 1959 to the new constitution of 2019
}

Albert Noguera Fernández

Universitat de València

albert.noguera@uv.es

http://dx.doi.org/10.18543/ed-67(1)-2019pp315-350

Recibido: 04.04.2019

Aceptado: 21.06 .2019

\section{Resumen}

En julio de 2018, la Asamblea Nacional de Cuba inició el trámite de discusión de un nuevo proyecto de Constitución, cuya aprobación, mediante referéndum, se produjo en febrero de 2019. Esta Constitución es la concreción jurídico-formal de todo un conjunto de transformaciones sociales y económicas que vienen produciéndose en la isla desde inicios de la década de los 90, con la caída del bloque socialista. El presente artículo lleva a cabo un análisis de las transformaciones que en materia de propiedad y de regulación del trabajo por cuenta propia se han producido durante este período, así como de las novedades que la nueva Constitución introduce en estos aspectos.

* Cómo citar / Citation 'Chicago-Deusto' (Autor-fecha / Author-date / Lista de referencias / Reference list entries): Noguera Fernández, Albert. 2019. «Regimen de propiedad y trabajo por cuenta propia en Cuba: De 1959 a la nueva Constitución de 2019». Estudios de Deusto 67, n. ${ }^{\circ}$ 1: 315-350. http://dx.doi.org/10.18543/ed-67(1)-2019pp315-350. El presente artículo se ha elaborado en el marco del Proyecto de I+D: «La Constitución climática global: gobernanza y Derecho en un contexto complejo» financiado por el Ministerio de Economía y Competitividad para el trienio 2017-2019 (proyecto DER201680011-P) 


\section{Palabras clave}

Cuba; Constitución; propiedad; trabajo por cuenta propia.

\section{Abstract}

In July 2018, the National Assembly of Cuba began the process of discussing a new draft Constitution, which was approved, by referendum, in February 2019. This Constitution is the legal-formal concretion of a whole set of social and economic transformations that have been taking place on the island since the early 1990s, with the fall of the socialist bloc. The present article carries out an analysis of the transformations that have occurred during the period in terms of property and regulation of self-employment, as well as of the new features that the new Constitution introduces in these aspects.

\section{Keywords}

Cuba; Constitution; property; self-employment. 


\begin{abstract}
SUMARIO: I. INTRODUCCIÓN. II. LA REVOLUCIÓN DE 1959 Y LA CONSTITUCIÓN DE 1976: PROPIEDAD Y TRABAJO POR CUENTA PROPIA EN LA PRIMERA FASE DE LA REVOLUCIÓN. III. LA REFORMA CONSTITUCIONAL DE 1992 Y SU LEGISLACIÓN COMPLEMENTARIA: LA AMPLIACIÓN DEL TRABAJO POR CUENTA PROPIA. 1. La propiedad de las empresas mixtas, sociedades y asociaciones económicas. 2. La propiedad agraria. 3. La ampliación del trabajo por cuenta propia. IV. LA RETIRADA DE FIDEL CASTRO Y LAS TRANSFORMACIONES DE LA DÉCADA 2007-2017. 1. Adelgazamiento del sector estatal, nueva ampliación del trabajo por cuenta propia y el Código del Trabajo de 2013. 2. La sindicalización del trabajo por cuenta propia. 3. Atracción y ampliación de la inversión extranjera. 4. Cambios en la propiedad agraria y reforma de la Ley de vivienda. V. LA CONSTITUCIÓN DE 2019 Y LOS NUEVOS REGIMENES DE PROPIEDAD EMERgentes. 1. La propiedad cooperativa. 2. Propiedad privada y privatizaciones. VI. CONCLUSIONES. VII. BIBLIOGRAFÍA.
\end{abstract}

\title{
I. INTRODUCCIÓN
}

En julio de 2018, la Asamblea Nacional del Poder Popular (ANPP) de Cuba inició el trámite de discusión y aprobación de la nueva Constitución de Cuba, aprobada en referéndum en febrero de 2019. El nuevo texto introduce novedades importantes tanto en el ámbito político como económico en Cuba. Uno de estos aspectos es el régimen de propiedad y vinculado a él, el trabajo por cuenta propia.

El presente trabajo analizará el régimen de propiedad establecido por la hasta hace poco vigente Constitución de 1976 y la regulación del trabajo por cuenta propia, las transformaciones producidas en éstos desde la caída del bloque socialista hasta la actualidad y la propuesta contenida en la nueva Constitución de 2019.

La necesidad de adelgazamiento de un amplio y, en muchos casos, ineficaz sector estatal, ha obligado a desarrollar otros tipos de propiedad y/o gestión de los medios de producción y servicios, así como a una fuerte ampliación del trabajo por cuenta propia. La actual Constitución abre la puerta a que ello se pueda hacer a través tanto de lo privado como de lo cooperativo. En función de por cuál de estos dos modelos se acabe optando, el devenir del socialismo en Cuba será uno u otro.

\section{LA REVOLUCIÓN DE 1959 Y LA CONSTITUCIÓN DE 1976: PROPIEDAD Y TRABAJO POR CUENTA PROPIA EN LA PRIMERA FASE DE LA REVOLUCIÓN}

El triunfo de la Revolución, el 1 de enero de 1959, implicó una reformulación del gobierno en Cuba. El 3 de enero de 1959, el Presidente de la 
República designó a Fidel Castro como Comandante en jefe de las Fuerzas de Tierra, Mar y Aire, declaró cesante en sus cargos a las personas que detentaban la presidencia de la República y las funciones legislativas, disolvió el Congreso de la República y sus funciones las asumiría a partir de entonces el Gobierno Revolucionario. Además, declaró cesantes en sus cargos a los alcaldes, concejales y gobernadores ${ }^{1}$.

Al mes siguiente, en febrero, el nuevo poder revolucionario aprobó un nuevo texto constitucional, denominado Ley Fundamental, que como establecía el programa del Moncada, estaba basado en la Constitución de $1940^{2}$. El nuevo texto reproducía íntegramente el redactado de la Constitución del 40 en su parte dogmática, sin embargo, introducía novedades en algunas partes, entre ellas, la estructura del aparato estatal ${ }^{3}$ o la regulación de la propiedad. En este sentido, se modificó el art. 24 del texto del 40, en cuanto que ahora se abría la posibilidad de expropiación sin previa indemnización ${ }^{4}$.

${ }^{1}$ Libro de Actas del Consejo de Ministros, Acta no.1, pp.2-4, Archivo del Comité Ejecutivo del Consejo de Ministros de la República de Cuba (citado por Martha Prieto, El orden constitucional cubano. Realidades y perspectivas [manuscrito inédito], Marzo 2005).

${ }^{2}$ La Constitución de 1940, aprobada en un contexto internacional especial, y por ello en un marco nacional muy radicalizado, contó, en los debates convencionales, con la presencia de una delegación de los comunistas de entonces, organizados en el Partido Unión Revolucionaria Comunista, los cuales, apoyándose en una extraordinaria movilización popular, lograron la redacción de un texto constitucional considerado de los más progresistas de América en esos momentos. No obstante, las grandes conquistas políticas y sociales de aquella Constitución quedaron en simple letra muerta, porque se difirieron a supuestas leyes complementarias que nunca llegaron a dictarse. (Julio Fernández Bulté, «Tras las pistas de la Revolución en cuarenta años de Derecho», Revista Temas, no 16-17 (1999): 105). No obstante, como afirma Martha Prieto, a pesar de las similitudes establecidas tradicionalmente entre la Constitución de 1940 y la Ley fundamental de 1959, no podemos olvidar que el carácter del proceso revolucionario y las medidas y declaraciones políticas del momento, nos obligan a interpretar los preceptos de la Ley fundamental, no de manera aislada o desde un punto de vista normativista, sino teniendo en cuenta el momento histórico y el papel de esta Ley en el asentamiento de las bases para una nueva institucionalidad, con la cual cosa podemos considerar la Ley fundamental de 1959 como un documento bien diferente al de la Constitución de 1940 (Martha Prieto, «Reflexiones en torno al carácter normativo de la Constitución», en Temas de Derecho constitucional cubano, comp. por Marta Prieto y Lissette Pérez (La Habana: Ed. Félix Varela, 2000), 33).

${ }^{3}$ la Ley fundamental había eliminado el antiguo poder legislativo bicameral (senado y cámara de representantes) y pasó sus facultades legislativas al Consejo de Ministros. El aparato de poder al amparo de la nueva Ley, se estructuró a nivel nacional a través de un Presidente de la República, como jefe de Estado, un Consejo de Ministros como máximo órgano constituyente, legislativo, ejecutivo y administrativo, y al frente de éste un Primer Ministro (Martha Prieto, El orden constitucional cubano. Realidades y perspectivas, Ibid.).

${ }^{4}$ Aunque la indemnización dejó de ser previa, los afectados recibieron una indemnización mediante bonos pagaderos en determinado tiempo y pago de cuotas vitalicias. La 
En estos primeros años, el Consejo de Ministros aprobó diferentes leyes de confiscación, de intervención y nacionalización. Entre 1959 y 1968 se implementan diferentes procedimientos legales correspondientes a tres etapas, que suponen un cambio radical de la estructura de propiedad en la isla. En concreto podemos distinguir ${ }^{5}$ :

Una primera etapa de confiscación que se desarrolló durante el propio 1959 y tuvo como objetivo esencial la confiscación los bienes pertenecientes a Fulgencio Batista y otros miembros del régimen derrocado, aunque también se dictaron otras disposiciones de carácter nacionalizador ${ }^{6}$.

Una segunda etapa de nacionalización mediante expropiación forzosa, por vía judicial o administrativa, con indemnización y por compra que tuvo lugar entre los meses de junio y octubre de 1960, nacionalizándose las principales empresas norteamericanas, haciéndose necesaria su recuperación para encausar el desarrollo económico del país?

Y, una tercera etapa caracterizada por la intervención directa de los organismos estatales, como paso previo a la confiscación, la nacionalización o la liquidación de la misma. En esta etapa, las medidas revolucionarias adoptaron la forma de respuesta a la reacción de los sectores de la burguesía nacional aliada a los Estados Unidos, dando como resultado la profundización de las nuevas relaciones de producción, y la plena configuración de la propiedad estatal socialista, comprendiendo este período de octubre de 1960 a marzo de $1968^{8}$.

Ley de Reforma Agraria, de 17 de mayo de 1959, la cual afectó por igual a cubanos y a extranjeros y marcó el inicio del proceso nacionalizador, establecía el pago de indemnización que se hizo mediante la emisión en bonos de la Reforma Agraria al 4,5\% anual, amortizables en 20 años (Olga Miranda, «Las nacionalizaciones cubanas», en Temas de Derecho constitucional cubano, Ibid.: 83).

5 Francisco E. García Henríquez, Yarelis Martínez Lorenzo y Jhosvany Martínez Barreiro, Compendio de disposiciones legales sobre nacionalización y confiscación (La Habana: Ministerio de Justicia, 2004), 48-147.

${ }^{6}$ Ley de Reforma Constitucional de 10 de enero de 1959; Ley de 13 de enero de 1959; Ley n. ${ }^{\circ} 112$, de 27 de febrero de 1959; Ley n. ${ }^{\circ} 270$, de 27 de abril de 1959; Primera Ley de Reforma Agraria, de 17 de mayo de 1959; Ley n. ${ }^{\circ} 351$, de 29 de mayo de 1959; Ley n. ${ }^{\circ} 381$, de 12 de junio de 1959; Ley n. ${ }^{\circ} 413$, de 19 de junio de 1959; Ley n. ${ }^{\circ} 438$, de 7 de julio de 1959; Ley n. ${ }^{\circ} 543$, de 2 de septiembre de 1959; Ley n. ${ }^{\circ} 617$, de 27 de octubre de 1959; Ley n. ${ }^{\circ} 647$, de 24 de noviembre de 1959; Ley n. ${ }^{\circ} 664$, de 23 de diciembre de 1959.

${ }^{7}$ En esta etapa se dictó: la Ley n. ${ }^{\circ} 851$, de 6 de julio de 1960; la Resolución n. ${ }^{\circ} 1$ del Consejo de Ministros, de 6 de agosto den1960; y, la Resolución n. ${ }^{\circ} 2$ del Consejo de Ministros, de 17 de septiembre de 1960.

${ }^{8}$ La legislación dictada fue: Resolución n.$^{\circ} 3$ del Consejo de Ministros, de 24 de octubre de 1960; Resoluciones del Consejo de Ministros, $\mathrm{n}^{\circ} 4$ de 28 de enero, $\mathrm{n}^{\circ} 5$ de 23 de mayo, n. ${ }^{\circ} 6$ de 14 de diciembre y n. ${ }^{\circ} 7$ de 3 de enero, de 1963; Resoluciones del Consejo de Ministros, n. $^{\circ} 8$ de 17 de abril, n. ${ }^{\circ} 9$ de 30 de diciembre, de 1964; Resolución n. ${ }^{\circ} 10$ del Consejo 
Al finalizar las nacionalizaciones de 1963, la propiedad estatal ocupaba en Cuba el 95\% de la industria, el 98\% de la construcción, el 95\% del transporte, el $70 \%$ de la agricultura, el $75 \%$ del comercio minorista y el $100 \%$ del comercio mayorista9 ${ }^{9}$ Tales cifras estaban muy cerca, de las de muchos países con más de dos décadas de socialismo.

Este amplio sector de la economía estatal, aún mayor después de la denominada «Ofensiva revolucionaria» que prorrogó las acciones confiscatorias hasta 1968, permitió la integración y el progresivo desarrollo en Cuba de las nuevas relaciones de producción y estructura socio-económica de carácter socialista.

\section{Estructura socio-clasista (del total de ocupados en la economía nacional en \%) 1970, 1980, 1988}

\begin{tabular}{|l|c|c|c|}
\cline { 2 - 4 } \multicolumn{1}{c|}{} & $\mathbf{1 9 7 0}$ & $\mathbf{1 9 8 1}$ & $\mathbf{1 9 8 8}$ \\
\hline Sector Estatal & $\mathbf{8 7 , 4 \%}$ & $\mathbf{9 1 , 8 \%}$ & $\mathbf{9 4 , 0 \%}$ \\
\hline Obreros de producción & $45,1 \%$ & $47,5 \%$ & $48,0 \%$ \\
\hline Obreros de servicios & $25,3 \%$ & $12,3 \%$ & $13,0 \%$ \\
\hline
\end{tabular}

de Ministros, de 17 de febrero de 1965; Ley n. ${ }^{\circ}$ 890, de 13 de octubre de 1960; Acuerdos de la Junta Central de Planificación de 7 de junio y de 21 de junio de 1961; Ley n. ${ }^{\circ} 891$, de 13 de octubre de 1960; Ley de Reforma Urbana, de 14 de octubre de 1960; Ley n. ${ }^{\circ}$ 923, de 4 de enero de 1961; Ley de Nacionalización de la Enseñanza, de 6 de junio de 1961; Ley n. ${ }^{\circ} 947$, de 27 de junio de 1961; Acuerdo de la Junta Central de Planificación de 30 de junio de 1961; Acuerdo n. ${ }^{\circ}$ IV de la Junta Central de Planificación, de 19 de junio de 1961; Acuerdo n. ${ }^{\circ}$ VII de la Junta Central de Planificación, de 30 de agosto de 1961; Acuerdo de la Junta Central de Planificación, de 17 de octubre de 1961; Acuerdo n. ${ }^{\circ}$ V de la Junta Central de Planificación, de 3 de noviembre de 1961; Acuerdo n. ${ }^{\circ}$ III de la Junta Central de Planificación, de 24 de noviembre de 1961; Acuerdo de la Junta Central de Planificación, de 8 de diciembre de 1961; Acuerdos de la Junta Central de Planificación, de 2 de abril, 25 de junio y 27 de julio de 1962; Ley n. ${ }^{\circ}$ 988, de 29 de noviembre de 1961; Ley n. ${ }^{\circ}$ 989, de 5 de diciembre de 1961; Ley n. ${ }^{\circ} 1028$, de 24 de mayo de 1962; Ley n. ${ }^{\circ} 1076$, de 4 de diciembre de 1962; Ley n. ${ }^{\circ} 1090$, de 1 de febrero de 1963; Segunda Ley de Reforma Agraria, de 3 de octubre de 1963; Ley n. ${ }^{\circ}$ 1320, de 27 de noviembre de 1976 -Ley de Asociaciones; Resoluciones del Instituto Nacional de Reforma Agraria No.596-706, de 27 de diciembre de 1960; Resoluciones del Instituto Nacional de Reforma Agraria n. ${ }^{\circ} 713$ de 8 de enero, n. ${ }^{\circ} 61-190$ de 16 de febrero y n. ${ }^{\circ}$ 61-194 de 7 de febrero, de 1961; Resoluciones del Ministerio de Industria n. ${ }^{\circ} 61-197$ de 12 de junio, n. ${ }^{\circ} 204$ y 207 de 31 de mayo, de 1961; Resolución de la Corporación Nacional de Transportes n. ${ }^{\circ}$ 6498, de 14 de octubre de 1960; Resolución del Ministerio del Interior n. ${ }^{\circ}$ 454, de 29 de septiembre de 1961; Resolución del Ministerio de Hacienda n. ${ }^{\circ}$, de 4 de enero de 1963; Ley n. ${ }^{\circ} 1188$, de 25 de abril de 1966.

9 Datos tomados de «Plan para la economía nacional de 1964», Revista Cuba Socialista, n. ${ }^{\circ} 3$ (1964). 


\begin{tabular}{|l|c|c|c|}
\cline { 2 - 4 } \multicolumn{1}{c|}{} & $\mathbf{1 9 7 0}$ & $\mathbf{1 9 8 1}$ & $\mathbf{1 9 8 8}$ \\
\hline Administrativos & $3,8 \%$ & $6,7 \%$ & $6,5 \%$ \\
\hline Técnicos & $9,0 \%$ & $17,7 \%$ & $20,1 \%$ \\
\hline Dirigentes & $4,2 \%$ & $7,6 \%$ & $6,4 \%$ \\
\hline Sector No Estatal & $\mathbf{1 2 , 6 \%}$ & $\mathbf{8 , 2 \%}$ & $\mathbf{6 , 0 \%}$ \\
\hline Campesinado tierras estatales & $44,4 \%$ & $44,4 \%$ & $44,4 \%$ \\
\hline Pequeño agricultor individual & $9,8 \%$ & $4,3 \%$ & $3,0 \%$ \\
\hline Cooperativista & - & $1,1 \%$ & $2,0 \%$ \\
\hline Trabajador por cuenta propia & $2,8 \%$ & $2,8 \%$ & $1,0 \%$ \\
\hline
\end{tabular}

Fuentes: JUCEPLAN. Boletín Estadístico de 1970. Comité Estatal de Estadística. Censos de población y vivienda 1970 y 1981. Comité Estatal de Estadística. Anuario Estadístico de Cuba de 1988. Tomado de: M. Espina. «Transformaciones recientes de la estructura socio-clasista cubana», Revista Papers, n. ${ }^{\circ} 52$ (1997).

Como vemos en el cuadro, las formas de trabajo por cuenta propia son prácticamente inexistentes. Como señaló Fidel Castro en el discurso pronunciado en el VIII aniversario del ataque al cuartel Moncada, el 26 de julio de 1961: «Hay infinidad de pequeños negocios, hay infinidad de «timbiriches», hay infinidad de pequeños talleres, hay infinidad de gente que trabaja por su propia cuenta $(\ldots)\rangle^{10}$. La estrategia del gobierno revolucionario fue intentar asimilar en el sector estatal a todos estos titulares de negocios, comercios y micro-establecimientos privados en los que se vendían productos alimenticios y otros, limitando el fenómeno del autoempleo. La manera utilizada para ello fue a través de la Ley Fiscal n. ${ }^{\circ} 998$ de 1962, donde se delinean los principios que deben regular, a partir de entonces, esta actividad laboral y la diferencian del trabajo privado. Tales principios fueron: despliegue de actividades autorizadas sobre la base del trabajo personal o la ayuda familiar, prohibición de establecimientos abiertos al público, imposibilidad de emplear personal asalariado, así como determinación administrativa de la especie de profesión, arte u oficio por cuya realización se obligaba a personas naturales al pago de un quantum impositivo ${ }^{11}$.

${ }^{10}$ Versiones taquigráficas del Gobierno Revolucionario (La Habana: Centro de Documentación del Comité Central del PCC), 3952.

11 Yuri Pérez, Fundamentos jurídicos para la armonización de intereses públicos y privados en sede de alojamiento turístico en Cuba [tesis doctoral], Universidad de La Habana, 2014, Disponible en: file://C:/Users/USER/Downloads/Fundamentos\%20juridicos\%20para\%20la\%20a\%20-\%20Perez\%20Martinez,\%20Yuri.pdf 
Todas estas restricciones redujeron al sector al mínimo. Se desterró del sector el ejercicio profesional privado. Aunque excepcionalmente, se mantuvieron profesiones determinadas, a modo de remanente: médicos, estomatólogos, optometristas, quiropodistas, veterinarios y mecánicos dentales. En 1976, desde el punto de vista legal, se excluyó de las actividades laborales por cuenta propia autorizadas, el ejercicio profesional de la medicina y la veterinaria. Tras la ininterrumpida actividad por parte de algunos profesionales privados, graduados con anterioridad al año 1964, se permitió, con carácter excepcional y observando los requisitos establecidos por los Organismos de la Administración Central del Estado competentes en la materia. Lo anterior se explica sobre la base de un acuerdo tomado por los estudiantes de medicina donde juraban ejercer la profesión de forma social y no de manera privada, cuestión que se expresó jurídicamente $^{12}$.

Llevadas a cabo todas estas transformaciones, las nuevas relaciones de producción y estructura socio-económica de carácter socialista quedaron institucionalizadas definitivamente con la Constitución socialista de 1976 y su legislación complementaria ${ }^{13}$.

La Constitución de 1976 reconoció como forma principal de propiedad, la propiedad socialista (Art. 14). Ésta puede adoptar tres formas distintas: la más importante, que es la propiedad estatal, integrada por los bienes colectivos que conforman el patrimonio del Estado; la propiedad cooperativa ${ }^{14}$; y la propiedad de las organizaciones políticas, de masas y sociales ${ }^{15}$.

Además, la Constitución permitía también algunas formas de propiedad individual: la propiedad de los pequeños agricultores sobre las tierras y

12 Ibid. p. 32.

13 Sobre el proceso de institucionalización del sistema jurídico y político socialista cubano véase Julio Fernández Bulté, «Problemas y desafíos de Cuba contemporánea: el sistema político y el sistema jurídico», ponencia presentada en el Taller Problemas y desafios para Cuba contemporánea (Notre Dame: Instituto Kellog para Estudios Internacionales, 1998).

${ }^{14}$ La propiedad cooperativa está integrada por los bienes que sus miembros aportan, y constituye una nueva forma de colectivización que destina su producción no sólo al beneficio de los cooperativistas, sino también al desarrollo de la producción agropecuaria en general. Esta característica esencial no la convierte en antagónica de la propiedad estatal socialista, pues tienen de común que los medios de producción son de carácter social, las relaciones personales son de colaboración y ayuda mutua y el fin en ambos es el mismo: solventar las múltiples demandas sociales. (Fernando Álvarez, Comentarios a la Constitución Socialista (La Habana: Editorial Pueblo y Educación, 1989), 83.

${ }^{15}$ Estas organizaciones políticas, de masas y sociales son consideradas sujetos de relaciones jurídicas y por ende, poseen patrimonio propio, determinado éste por los estatutos o reglamentos que establecen los fines que se proponen y que se cumplimentan con sus bienes, sobre los que tienen el derecho de propiedad (Ibid.). 
demás bienes agropecuarios (Art. 19) y la propiedad personal ${ }^{16}$ (Art. 21). Dentro de ésta última incluimos también la propiedad sobre los medios e instrumentos de trabajo personal o familiar que no se empleen para explotar trabajo ajeno, sobre la que se fundamenta la actividad por cuenta propia.

\section{LA REFORMA CONSTITUCIONAL DE 1992 Y SU LEGISLACIÓN COMPLEMENTARIA: LA AMPLIACIÓN DEL TRABAJO POR CUENTA PROPIA}

El desplome vertiginoso del campo socialista en 1989 y en consecuencia, la desaparición repentina para Cuba del orden internacional al que se encontraba orgánicamente articulada, se tradujo en una profunda crisis para su economía, la cual fue profundizada con el recrudecimiento del bloqueo norteamericano. En este contexto, la introducción de reformas para hacer frente a la fuerte crisis económica empieza a partir de la celebración del IV Congreso del PCC, en octubre de 1991, y tuvo su expresión jurídica en la Ley de Reforma Constitucional de 12 de julio de 1992. Entre otros aspectos, la reforma introdujo cambios en las formas de propiedad y una importante ampliación del ámbito del trabajo por cuenta propia.

La reforma del art. 14 constriñó la posesión exclusiva del Estado sobre «todos los medios de producción» a sólo aquellos «medios fundamentales de producción», pasando a describir en el art. 15 cuáles son estos medios fundamentales de producción ${ }^{17}$. Asimismo, si bien el art. 15 mantiene la prohibición de que estos sean transmitidos en propiedad a personas naturales o jurídicas, establece, ahora, una excepción autorizante a la formulación negativa general, permitiendo la transmisión en «casos excepcionales en que la transmisión parcial o total de algún objetivo económico se destine a los fines de desarrollo del país y no afecte los fundamentos políticos, sociales y económicos del Estado, previa aprobación del Consejo de Ministros o su Comité Ejecutivo».

${ }^{16}$ La propiedad personal incluye el derecho de propiedad sobre los ingresos y ahorros procedentes del trabajo propio, sobre la vivienda que se posea con justo título de dominio y los demás bienes y objetos que sirven para la satisfacción de las necesidades materiales y culturales de la persona.

${ }^{17}$ De acuerdo con el citado art. 15, éstos son: a) las tierras que no pertenecen a los agricultores pequeños o a cooperativas integradas por estos, el subsuelo, las minas, los recursos naturales tanto vivos como no vivos dentro de la zona económica marítima de la República, los bosques, las aguas y las vías de comunicación; b) Los centrales azucareros, las fábricas, los medios fundamentales de transporte, y cuantas empresas, bancos e instalaciones han sido nacionalizados y expropiados a los imperialistas, latifundistas y burgueses, así como las fábricas, empresas e instalaciones económicas y centros científicos, sociales, culturales y deportivos construidos, fomentados o adquiridos por el Estado y los que en el futuro construya, fomente o adquiera. 


\section{La propiedad de las empresas mixtas, sociedades y asociaciones económicas}

Ello abrió un espacio en la economía cubana para el desarrollo de la propiedad mixta. El Art. 23 reconoce, ahora explícitamente, la propiedad de las empresas mixtas, sociedades y asociaciones económicas que se constituyan conforme a la ley. E incluso, abre la opción para la posibilidad, si en algún momento futuro el Consejo de Ministros o su Comité Ejecutivo lo considerase oportuno, de una propiedad íntegramente privada. Antes de este reconocimiento constitucional, la posibilidad de creación de empresas mixtas o de contratos de asociación económica internacional como modalidad de inversión extranjera, había estado ya prevista por el Decreto-Ley n. ${ }^{\circ} 50$ de 1982. Éste había sido aprobado con el objetivo de propiciar y regular, en ocasiones excepcionales, el establecimiento de relaciones con entidades o empresas extranjeras sobre todo capitalistas, para la obtención de capital, tecnología y mercado. Sin embargo, la confusión sobre la constitucionalidad o inconstitucionalidad del Decreto-Ley ${ }^{18}$ no otorgaba al inversionista foráneo certidumbre y seguridad para la ejecución de sus proyectos económicos y su aplicación práctica fue muy poco relevante. El número de Asociaciones Económicas Internacionales en 1990, era de $3^{19}$. Es a partir de 1992 cuando este instrumento legal empieza a regir dentro de un marco de clara constitucionalidad que se produce un importante incremento de la inversión suscrita por capital extranjero.

En 1995 el fenómeno de la inversión adquiere plena configuración legal con la aprobación de la Ley No.77 de Inversión Extranjera, la cual establece la posibilidad de autorizar inversiones extranjeras en todos los sectores, con la excepción de los servicios de salud y educación a la población y las instituciones armadas, salvo en su sistema empresarial ${ }^{20}$. En cuanto a las formas,

${ }_{18}$ Por un lado, el no reconocimiento de forma taxativa en la Constitución de esta forma de propiedad podía servir para fundamentar una presumible inconstitucionalidad de la misma, sin embargo, por otro lado, ejemplos como el del reconocimiento en el Código Civil aprobado por la Ley 59 de 16 de julio de 1987, de las Fundaciones como sujeto de derechos y obligaciones (art. 39.1.d), demostraban la posibilidad de existencia armónica de otras formas de propiedad menores junto a aquellas fundamentales reconocidas en la Constitución.

${ }^{19}$ Carlos García Valdés. «La economía cubana de los años 90: transformaciones en la economía socialista», en Economía: Análisis, propuestas, alternativas, comp. Por Carlos García Valdés et.al. (La Habana: Ed. Ciencias Sociales, 1998), 40.

${ }^{20}$ Hasta 1991 la inversión extranjera había estado dirigida, principalmente, hacia el sector del turismo. A partir de ese año, la posibilidad de inversión se abrió progresivamente. En 1992 está ya abierta en todas las ramas consideradas no estratégicas e incluso algunas de estas últimas como la comercialización de productos farmacéuticos de base biotecnológica. En 1993 se acepta la posibilidad de representaciones de bancos extranjeros en Cuba para ampliar la infraestructura de servicios financieros al resto de la inversión extranjera que opera en el país. Y, en octubre de 1994, el gobierno cubano mediante discur- 
el art. 12 de la Constitución señala que las inversiones extranjeras adoptarán alguna de las siguientes formas: empresa mixta, contrato de asociación económica internacional o empresa de capital totalmente extranjero ${ }^{21}$. Tanto el Decreto-Ley 50/82 como la Ley 77/95, limitan el alcance de la preceptiva constitucional al capital procedente del exterior excluyendo la posibilidad de formación de una propiedad privada nacional ${ }^{22}$.

El conjunto de estas transformaciones en las formas de propiedad junto a la nueva regulación del comercio exterior, produjeron un aumento en la presencia de empresarios extranjeros y de turistas que llevará consigo la aparición de una red comercial en divisa destinada a la población no nacional. Pero también, la disposición creciente de divisas en manos de la población, ya sea por ingresos en concepto de propinas o regalos recibidos por trabajadores cubanos en empresas extranjeras o vinculadas al turismo, por negocios ilegales de sectores de la ciudadanía con turistas o empresarios, y principalmente, por remesas familiares exteriores en dólares (se estima que entre 1989 y 1996 se ingresaron en el país por concepto de remesas familiares alrededor de 3.000 millones de dólares) ${ }^{23}$.

so de Carlos Lage (Secretario del Consejo de Ministros y su Comité Ejecutivo y miembro del Consejo de Estado) en la inauguración de la XII Feria Internacional de La Habana (31 octubre 1994), anunció que ningún sector productivo de la economía nacional estaba cerrado a la inversión extranjera (Carlos Lage, «Discurso en la inauguración de la XII Feria Internacional de La Habana», en Periódico Granma, 1 de noviembre de 1994; Vid. también Julio Carranza, Luis Gutiérrez y Pedro Monreal, Cuba: la reestructuración económica. Una propuesta para el debate (La Habana: Ed Ciencias Sociales, 1995).

${ }^{21}$ En el Art. 2 de la Ley aparecen definidas cada una de estas formas de inversión de la siguiente manera: Empresa mixta: Compañía cubana que adopta la forma de Sociedad Anónima por acciones nominativas, en la que participan como accionistas uno a más inversionistas nacionales y uno o más inversionistas extranjeros; Contrato de asociación económica internacional: Pacto o acuerdo entre uno o más inversionistas nacionales y uno o más inversionistas extranjeros, para realizar conjuntamente actos propios de una asociación económica internacional, aunque sin constituir persona jurídica distinta las partes; y, Empresa de capital totalmente extranjero: Entidad mercantil con capital extranjero, sin la concurrencia de ningún inversionista nacional.

${ }_{22}$ En el año 1996 existían en Cuba 260 Asociaciones Económicas Internacionales (éstas comprenden empresas mixtas y contratos de asociación económica internacional) de más de 50 países. En 1997 el número de AIE es de 317 y al concluir el año se estudiaban más de 120 proyectos de asociación («Cuba. La economía al cierre de 1997», en Revista Cuba Socialista, n. 9 (1998): 46). En el año 2000, se concertaron 31 negocios entre empresas mixtas y contratos de asociación. En total, desde el inicio del proceso de apertura hasta el 2001, el monto de inversión directa contratada es de alrededor 5.000 millones de dólares (Juan Triana, «La transformación económica en el socialismo», Academia. Revista del Colegio de Ciencias Sociales y Humanidades de la Universidad de La Habana, n. 1 (2001): 23).

${ }^{23}$ Vid. Hiram Marquetti, La economía del dólar: balance y perspectivas, revista TEMAS, n. ${ }^{\circ} 11$ (1997). 
Ésta situación trajo como principal consecuencia que el gobierno cubano aprobase en 1993 del Decreto-Ley No.140 de despenalización de la tenencia de divisas, por el que se legalizó la tenencia y operación en divisas en todo el territorio nacional para los ciudadanos cubanos. Creándose, en consecuencia, en el plano económico interno, una economía de carácter dual.

\section{La propiedad agraria}

Respecto a la agricultura, la reforma no implicó un cambio en las formas de propiedad de la tierra. En esos momentos, la propiedad estatal abarcaba aproximadamente el $82 \%$ de la superficie total de la tierra cultivable del país, la propiedad cooperativa (Cooperativas de Producción Agropecuaria) ocupaban el $8 \%$ y la propiedad privada de los pequeños agricultores (Cooperativas de Crédito y Servicios o miembros de Asociaciones Campesinas) el 10\% ${ }^{24}$. No obstante, sí que se producen transformaciones con respecto a la forma de gestión de la más importante de estas formas, la propiedad estatal de la tierra.

A partir de 1993 las grandes extensiones de tierra que ocupaban las granjas o empresas agrícolas del Estado, son fragmentadas mediante el Decreto-Ley No.142 de septiembre de 1993 en pequeñas formas de producción cooperativa denominadas Unidades Básicas de Producción Cooperativa (UBPC). Estas se caracterizan por el hecho de que la propiedad jurídica de la tierra continúa siendo del Estado que la cede a los productores asociados en usufructo gratuito por tiempo indefinido, pero ahora los productores asociados cooperativizan o son dueños del producto y sus ganancias. En cuanto a los medios de producción, los productores los comprarán a crédito al Estado. ${ }^{25}$

Si bien la Constitución de 1976 ya reconocía como forma de propiedad agropecuaria la cooperativa, ahora el texto constitucional añade en el art. 20: «(...) esta propiedad cooperativa es reconocida por el Estado y constituye

${ }^{24}$ Albert Noguera, Derecho y Hegemonía. Un estudio socio-jurídico de la Cuba actual (Buenos Aires: Ediciones Cooperativas, 2007), 117.

${ }^{25}$ El debate teórico sobre la naturaleza jurídica de esta forma organizativa, las UBPC, sus posibilidades y limitaciones, se reflejó desde sus inicios. Según el punto de vista de los modelos cooperativos, se considera que su creación constituye un rescate del cooperativismo estatal; con un carácter híbrido, por su dualismo funcional y estructural. Por su funcionamiento, se sitúa entre una unidad comercial y una unidad técnico-productiva; y por su estructura está a medio camino entre la empresa estatal y una verdadera cooperativa. Por otra parte, varios especialistas consideran que su carácter de cooperativa solo reside en su producción cooperada. En cuanto el sujeto que se integra a las UBPC, algunos lo definen por su pertenencia a una cooperativa estatal, por el medio estatal del que proviene y su relación con la propiedad de los principales medios de producción. Otros criterios caracterizan a este sujeto a partir de su participación en la gestión. (Niurka Pérez y Dayma Echevarría, «Participación y producción agraria en Cuba: las UBPC», Revista Temas, n. ${ }^{\circ} 11$ (1997): 71). 
una forma avanzada y eficiente de producción socialista. (...) El Estado brinda todo el apoyo posible a esta forma de producción agropecuaria».

Aunque la fragmentación de la tierra en las UBPC perseguía la creación de un nuevo sistema de estímulos con el objetivo de hacer aumentar la producción disminuyendo el gasto en los recursos materiales, las UBPC tenían como único comprador al Estado que además, planificaba los niveles de entrega y fijaba los precios. La imposibilidad de acceso directo al mercado con excedentes hacía que los trabajadores agrícolas ahora constituidos como propietarios socialistas ${ }^{26}$, continuaran siendo en la práctica asalariados estatales y por lo tanto el poder de estímulo de la medida era muy limitado. Durante el primer año de su creación, en 1993, el 59 \% de las UBPC no cañeras proyectaban pérdidas para 1994 (30,6 millones de pesos) ${ }^{27}$.

Eso fue una de las causas que llevó en 1994, mediante el Decreto No.191 del Consejo de Ministros emitido el 19 de septiembre y Resolución Conjunta de los Ministros de Agricultura y Comercio Interior de 20 de septiembre, a la apertura de los Mercados Agropecuarios, donde pueden concurrir con sus excedentes todos los agentes vinculados a la producción agropecuaria y los precios se determinan por la oferta y la demanda. Se introducen por tanto, mecanismos de mercado y flexibilización de la comercialización en la agricultura nacional.

\section{Estructura de tierra según propiedad (\% del total) ${ }^{28}$}

\begin{tabular}{|l|c|c|}
\hline \multicolumn{1}{|c|}{ Tierra Cultibable } & $\mathbf{1 9 9 2}$ & $\mathbf{1 9 9 6}^{\mathbf{2 9}}$ \\
\hline Estatal & 75,2 & 33 \\
\hline Cooperativas de Producción Agropecuaria (CPA) & 10,2 & 10 \\
\hline Unidades Básicas de Producción Cooperativa (UBPC) & - & 42 \\
\hline Cooperativas de Créditos y Servicios (CCS) y campesinos dispersos & 14,6 & 15 \\
\hline
\end{tabular}

Fuentes: Ministerio de la Agricultura e Informe de Carlos Lage al V Pleno del Comité Central del PCC. La Habana. 23 de abril de 1996.

${ }^{26}$ El concepto de propietarios socialistas es utilizado por Víctor Figueroa en «El nuevo modelo agrario en Cuba bajo los marcos de la reforma económica», en Desarrollo rural y participación (La Habana: Ediciones de la Universidad de La Habana, 1996).

27 Ver Boletín de Información Económica, IPS, no 30 (1994).

${ }^{28}$ Fuentes: Ministerio de la Agricultura e Informe de Carlos Lage al V Pleno del Comité Central del PCC, La Habana, 23 de abril de 1996.

${ }_{29}$ Para 1996, la estructura es sobre la base de la forma de explotación de la tierra ya que las tierras de las UBPC continúan siendo propiedad del Estado, y por otra parte, se mantiene el amplio dominio del sector socialista en la agricultura, con el $85 \%$ al igual que en 1992 y en los años anteriores. 
En resumen, con las medidas introducidas por la reforma: a) fraccionamiento de la gran propiedad estatal para la creación de las UBPC; b) establecimiento de asociaciones con capital extranjero; $y, c)$ reparto en régimen de usufructo de las tierras ociosas a los interesados en hacerlas producir; se produce una diversificación en la tenencia de la tierra y por tanto, una reorganización de la producción, quedando desde este momento, dividida en nueve formas diferentes agrupadas en cuatro sectores: sector estatal (empresa estatal, granjas EJT, granjas del MININT); sector cooperativo (UBPC, CPA); sector privado (campesino individual -CCS, AC-, usufructuario individual o familiares); y sector mixto (empresas mixtas).

\section{La ampliación del trabajo por cuenta propia}

Conjuntamente con lo anterior, en 1993 por cuanto el desarrollo y organización de la economía nacional imposibilitaba que las empresas o unidades presupuestadas estatales pudieran asegurar determinados servicios y productos necesarios para la población, que de hecho ya se estaban prestando en el marco de la economía sumergida, se aprueba el Decreto-Ley n. ${ }^{\circ} 141$ y la Resolución No.1 del Comité Estatal de Trabajo y Seguridad Social - Comité Estatal de Finanzas (CETSS-CEF) de 8 de septiembre.

Esta regulación reconoce el trabajo por cuenta propia como una alternativa de empleo en 115 actividades para una parte de la población. Los precios de estos servicios o productos se establecerán a partir de la relación oferta-demanda y en el tipo de moneda acordada por quienes participen en la transacción ${ }^{30}$. No obstante, se mantiene como política de Estado, la exclusión del ámbito del trabajo por cuenta propia de los graduados universitarios, bajo el fundamento de que debían entregar sus conocimientos a las necesidades del país y en beneficio de toda la sociedad que costeó de forma total y gratuita la formación. Así como de dirigentes políticos o administrativos, militares, funcionarios, jueces, fiscales o los que ostentaron cualquier cargo público similar.

${ }^{30}$ Antes de 1993, el Decreto-Ley n. ${ }^{\circ} 14$ de 3 de julio de 1978 había abierto la posibilidad de realizar actividades laborales por cuenta propia en aquellos ámbitos que la economía nacional no podía cubrir. Esta legislación pero, establecía unos límites muy estrechos: permitía el trabajo no estatal en determinadas actividades sólo como una fuente adicional de ingresos para trabajadores con vínculo laboral-estatal o jubilados, permitiéndoles vender su producto sólo a entidades estatales y organizaciones sociales o políticas, no a intermediarios o a la población. Además, por la Resolución Conjunta n. ${ }^{\circ} 14$ de 1982 del CETSS y el CEF se prohibía el ejercicio de estas actividades a los graduados de nivel superior y técnico medio -excepto cuando se demuestre la imposibilidad de encontrar empleo estatal- y a los dirigentes de entidades estatales. Tales medidas adoptaron un carácter aún más restrictivo con el proceso de rectificación iniciado en 1986. 
Además, el Estado tampoco se retiró de ninguna actividad, continuando prestando aquellos servicios en los que concurrían, ahora, los trabajadores por cuenta propia (barberías, peluquerías, sastrerías, etc.).

En el periodo de 1996 a 2010, se introdujeron más modificaciones lega$1 \mathrm{~s}^{31}$ en el sentido de ampliar el trabajo por cuenta propia: se permitió mediante autorización el ejercicio de la modalidad laboral a profesionales universitarios, siempre que no fuera en la profesión o especialidad de graduación. Ampliación de los sujetos cuentapropistas a personas trabajadores disponibles pendientes de reubicación y a aquellos desvinculados laboralmente. Autorización a ciudadanos cubanos y extranjeros residentes permanentemente en el territorio nacional, etc.

Aunque, seguramente, una de las principales novedades fue que desde 1996 los familiares ayudantes fueron considerados como cuentapropistas al igual que titular de la actividad. Atrás quedó la colaboración y cooperación familiar, pues el auxilio podía ahora prestarlo, además de cónyuges, padres, hermanos e hijos, también los convivientes, familiares o no, del trabajador autorizado a prestar el servicio. Además, se estableció sobre el ayudante un impuesto de un $20 \%$ del regulado para la actividad en la cual se ayudaba, de lo cual se desprendía que mediaba retribución en concepto de salario. El hecho de que esta medida no fuera acompañada de la regulación de derechos y garantías de este conviviente no familiar que trabajaba en la actividad, dio margen a la desprotección de estos trabajadores ${ }^{32}$.

El conjunto de estos cambios llevó a muchos trabajadores del sector estatal a pasarse al trabajo por cuenta propia, ya que éste se presentaba como una esfera de actividad donde se obtienen mayores ingresos. En 1988 el porcentaje de población ocupada en el sector estatal era, como ya hemos señalado,

31 Entre las disposiciones jurídicas que regularon la materia se encuentran: Resolución Conjunta $n .^{\circ} 1$ «Reglamento sobre el ejercicio del trabajo por cuenta propia» de fecha 18 de abril de 1996 del Ministerio de Trabajo y Seguridad Social y el Ministerio de Finanzas y Precios. Gaceta Oficial de la República de Cuba, edición ordinaria, número 19, año XCIV, pp. 137 y ss.; Resolución Conjunta n. ${ }^{\circ} 1$ del Ministerio de Trabajo y Seguridad Social y el Ministerio de Finanzas y Precios de fecha 10 de abril de 1998 modificativa del «Reglamento sobre el ejercicio del trabajo por cuenta propia». Gaceta Oficial de la República de Cuba, edición ordinaria, número 22, año XCVI, lunes 4 de mayo de 1998, La Habana, pp. 379 y ss.; Resolución n. ${ }^{\circ} 8$ de fecha 31 de marzo de 2003 de Ministro de Trabajo y Seguridad Social; Resolución n. ${ }^{\circ} 11$ de fecha 25 de marzo de 2004del Ministro de Trabajo y Seguridad Social. Gaceta Oficial de la República de Cuba, edición extraordinaria, número 32, martes 11 de mayo de 2004, La Habana, pp. 2 y ss.; Resolución n. ${ }^{\circ} 9$ de fecha 11 de marzo de 2005 del Ministro Trabajo y Seguridad Social. Gaceta Oficial de la República, edición extraordinaria, número 13, miércoles 25 de mayo de 2005, La Habana, pp. 1 y ss.

32 Yuri Pérez, Fundamentos jurídicos para la armonización de intereses públicos y privados en sede de alojamiento turístico en Cuba, Ibid.: 40. 
de un $94 \%$ mientras que el 6\% lo estaba en el sector privado. En 1994 la cifra de ocupados en el sector estatal ha disminuido a un $69,8 \%$ y la del sector privado ha aumentado a $21,8 \%$.

Según datos del Anuario Estadístico de 1988 los trabajadores no estatales se cifraban en este año en 41.400. En 1995 la Dirección de Ministerio de Trabajo y Seguridad Social los contaba en 208.346. Si tomamos en cuenta, dice J. Núñez, que sobre la base de parámetros internacionales calculados por la Organización Internacional del Trabajo (OIT) y de la experiencia de América Latina, especialistas del Centro de Estudios Laborales y del Trabajo han encontrado que por cada trabajador por cuenta propia existen como promedio 3,5 no registrados que pueden ser ayudantes familiares o no, la cifra se convierte en 1.094.100 que significan el $21 \%$ de los ocupados en la economía nacional ${ }^{33}$. Mayra Espina sitúa esta cifra, en sus estimaciones, alrededor del 30,2\%. El hecho que del conjunto de trabajadores registrados en el sector no estatal en 1995, el 74\% fueran hombres (datos MTSS), cuando muchas de estas actividades tienen un carácter familiar o implican tareas tradicionalmente consideradas femeninas, deja entrever que junto a ellos están involucradas también un alto número de mujeres ${ }^{34}$. Cifras oficiales de la Oficina Nacional de Estadística (Anuario Estadístico de Cuba de 1998 y 2002) cuantifican los empleados en el sector no estatal en: 1996, $18,9 \%$ de la población; $1997,19,5 \% ; 1998,20,5 \% ; 1999,22,0 \% ; 2000$, $22,5 \% ; \mathrm{y}, 2001,23,4 \%{ }^{35}$. En La Habana, al cierre del 2000, el sector informal empleaba 84.400 personas, experimentando respecto a 1999 , un crecimiento del 7,2\%, entre 1992 y 1999 los ocupados en entidades estatales decrecieron en la capital, de 885,3 miles de trabajadores a 773,9 , que representa el $25,9 \%$ del total de ocupados en este sector ${ }^{36}$.

\section{LA RETIRADA DE FIDEL CASTRO Y LAS TRANSFORMACIONES DE LA DÉCADA 2007-2017}

Ubicaremos el inicio de este segundo periodo de transformaciones con el abandono, en julio de 2006, de la dirección política del país por parte de Fidel

${ }^{33}$ Liliana Nuñez, «Más allá del cuentapropismo en Cuba», Revista Temas, n. ${ }^{\circ} 11$ (1997).

${ }^{34}$ Mayra Espina, «Reforma económica y reestratificación de la estructura socio-clasista cubana», Revista Academia, nº1-2 (2001): 27.

${ }_{35}$ Mayra Espina. «Reestratificación y desigualdad», en Mayra Espina et.al. Heterogeneidad social en la Cuba actual (La Habana: Centro de Estudios de Salud y Bienestar Humano, 2004), 19.

${ }_{36}$ Maricela Perera, La subjetividad en grupos de la capital [Mecanuscrito inédito] (La Habana: Fondos del Centro de Investigaciones Psicológicas y Sociológicas, 2002), 7-8. 
Castro. A partir de este momento, y con Raúl Castro al frente, se activa otro paquete de transformaciones del modelo socio-económico, plasmadas en múltiples modificaciones a leyes, decretos-leyes, decretos y reglamentos.

Como afirma Mylai Burgos ${ }^{37}$, dichas transformaciones han tenido tres momentos clave: sus inicios, desde 2006 con mayor consolidación a partir de 2008. Posteriormente, el VI Congreso del PCC, en abril de 2011, y los lineamientos de políticas económicas y sociales surgidos de él que tuvieron un proceso previo de discusión participativa en el seno de la sociedad. Y, por último, el restablecimiento de las relaciones diplomáticas con Estados Unidos, a partir de 2015 .

\section{Adelgazamiento del sector estatal, nueva ampliación del trabajo por cuenta propia y el Código del Trabajo de 2013}

Uno de los cambios con más trascendencia en este periodo fue el anuncio por parte de Raúl Castro, siguiendo el punto 169 de los lineamiento de la política económica y social del VI Congreso del $\mathrm{PCC}^{38}$, de la necesidad por cuestiones de eficiencia del sector estatal, de una reordenación laboral del país consistente en el desplazamiento de 500 mil trabajadores del sector público hacia el sector privado (arrendamiento o usufructo, las cooperativas y el trabajo por cuenta propia), en un plazo no mayor a seis meses entre finales de 2010 y el primer trimestre de 2011.

Para facilitar esta transición, se llevaron a cabo reformas en la legislación reguladora del trabajo por cuenta propia. El mismo 2010 se aprobó la Resolución n. ${ }^{\circ}$ 32/2010 del Ministerio de Trabajo y seguridad Social, complementada con un sinfín de normas ${ }^{39}$.

${ }^{37}$ Mylai Burgos, «Análisis Crítico Constitucional de los Cambios Socio-jurídicos en la Cuba Actual», Revista Direito \& Práxis, n. ${ }^{\circ} 4$ (2017): 3179.

${ }^{38}$ Este punto establece: «Desarrollar un proceso de reordenamiento laboral en el país que, bajo el principio de la idoneidad demostrada, contribuya a eliminar las plantillas infladas y los tratamientos paternalistas, para estimular la necesidad de trabajar y reducir los gastos de la economía y el Presupuesto del Estado»».

${ }^{39}$ Decreto-Ley n. $^{\text {o }} 275$ de 30 de septiembre de 2010, «Modificativo del Decreto Ley n. ${ }^{\circ}$ 171/97, Del Régimen de arrendamiento de Viviendas, habitaciones o espacios»; Resolución n. 305 de 7 de octubre de 2010, del Presidente del Instituto Nacional de la Vivienda, que aprueba el Reglamento del Arrendamiento de viviendas, habitaciones y espacios; Resolución n. ${ }^{\circ} 399$ de 7 de octubre de 2010, del Ministro del Transporte, que aprueba el Reglamento de la licencia de operación de transporte para personas naturales; Resolución n. ${ }^{\circ} 750$ de 7 de octubre de 2010, del Ministro de la Agricultura, que regula la contratación de trabajadores agrícolas asalariados permanente y trabajadores agrícolas eventuales; Resolución n. ${ }^{\circ} 33$ de 7 de octubre de 2010, de la Ministra de Trabajo y Seguridad Social, que regula la contratación por las Cooperativas de créditos y servicios de trabajadores permanentes asalariados para que trabajen junto a los Agricultores pequeños y por los agricultores pequeños, 
Un año más tarde, fue sustituida por la Resolución n ${ }^{\circ}$ 33/2011, de la Ministra de Trabajo y Seguridad Social, «Reglamento del ejercicio del trabajo por cuenta propia».

El objetivo de todas estas reformas fue ampliar y flexibilizar las actividades por cuenta propia. Entre otras medidas, destaca: la posibilidad, a partir de ahora, de que todos los ciudadanos cubanos y extranjeros residentes permanentemente en el país, mayores de 17 años pueden ejercer el trabajo por cuenta propia cumpliendo los requisitos establecidos; La aceptación del desarrollo de más de una actividad por cuentapropista; El levantamiento de la prohibición de comercializar productos y servicios a entidades estatales, dentro de los límites financieros definidos; La realización de la actividad por cuenta propia en otros lugares diferentes al domicilio del titular; Se amplían a 181 las actividades que se pueden realizar; Se establece la posibilidad de la utilización de fuerza de trabajo asalariada subordinada y dependiente de cuentapropistas para todas las actividades permitidas, estableciéndose en algunos casos límites de personas a contratar; Aumentan de 20 a 50 el número de sillas de que pueden disponer los elaboradores-vendedores de alimentos y bebidas mediante servicio gastronómico; y, también se exonera del pago del impuesto por la utilización de la fuerza de trabajo a los que contrataban hasta 5 trabajadores, entre otras.

Además, se autoriza la concesión de créditos bancarios para los cuentapropistas en aras a que puedan invertir en sus negocios, se introducen cambios en el régimen de tributación y se fija, mediante el Decreto-Ley n. ${ }^{\circ} 278 / 2010$ de 30 de septiembre, un régimen especial de Seguridad social para los trabajadores por cuenta propia que no son sujetos del régimen general de la Seguridad Social o cualquier otro régimen especial.

de los servicios de trabajadores agropecuarios eventuales que ejercen el trabajo por cuenta propia; Resolución n. ${ }^{\circ} 34$ de 7 de octubre de 2010, de la Ministra de Trabajo y Seguridad Social, que aprueba el procedimiento para la afiliación al régimen especial de seguridad social para los trabajadores por cuenta propia; Decreto-Ley n. ${ }^{\circ} 277$ de 30 de septiembre de 2010, «Modificativo del Decreto-Ley n. ${ }^{\circ} 169$, de las normas generales y de procedimientos tributarios»; Resolución n. ${ }^{\circ} 286$ de 7 de octubre de 2010, de la Ministra de Finanzas y Precios, que aprueba las normas relativas al pago de los impuestos sobre los ingresos personales, las ventas, los servicios públicos, por la utilización de la fuerza de trabajo, y las referentes al pago de la contribución a la seguridad social por los trabajadores por cuenta propia; Resolución n. ${ }^{\circ} 287$ de 7 de octubre de 2010, de la Ministra de Finanzas y Precios, que establece el impuesto sobre servicios públicos, en lo concerniente al arrendamiento de viviendas, habitaciones y espacios; Resolución n. ${ }^{\circ} 289$ de 7 de octubre de 2010, de la Ministra de Finanzas y Precios, que establece el pago en pesos cubanos del impuesto sobre documentos, para trámites de inscripción y reinscripción en el registro de contribuyentes, de los trabajadores por cuenta propia, con independencia de la moneda en que operan Decreto-Ley n. ${ }^{\circ} 274$ de 30 de septiembre de 2010, Modificativo del Decreto-Ley n. ${ }^{\circ}$ 174/97, «De las contravenciones personales de las regulaciones del trabajo por cuenta propia». 
En materia de Seguridad social, la afiliación al régimen especial de Seguridad Social de estos trabajadores es obligatoria y constituye un requisito indispensable para que ejerzan su trabajo y reciban beneficios de la Seguridad Social. El mismo ofrece protección al cuentapropista ante la vejez, la invalidez parcial o permanente y, en caso de muerte, a su familia, así como a la trabajadora con ocasión de la maternidad ${ }^{40}$ (arts. 1, 2 y 3 del Decreto-ley n. $\left.{ }^{\circ} 278\right)^{41}$.

Esta flexibilización del trabajo por cuenta propia implica un cambio importante respecto la existencia de este sector, el cual, si bien antes era visto con recelo, aunque se lo aceptaba como irremediable y necesario ante la situación económica, ahora pasa a verse como plenamente compatible con la esfera pública, dentro de los contornos de la transición socialista.

Aunque no se ha logrado desplazar hacia el sector privado a toda la cantidad de trabajadores prevista, sí se ha producido un fuerte incremento del mismo. Cuando se aprobó la ampliación y flexibilización del trabajo por cuenta propia, en septiembre-octubre del año 2010, ejercían esta modalidad unas 157 mil personas. En agosto del año 2011 ya eran 333.206. En mayo de 2017, ya eran 556.064 las personas inscritas en esa forma de empleo (un 12\% del total de ocupados del país), y las cifras continúan en ascenso ${ }^{42}$. Entre las

${ }^{40}$ Alcides Francisco Antúnez, Carlos Justo Bruzón y Sudis María Velázquez, «Un análisis a partir de la constitución cubana sobre el ejercicio del autoempleo: incidencias en el nuevo relanzamiento del modelo económico del siglo XXI», Foro, vol. 16, n. ${ }^{\circ} 1$ (2013): 75.

${ }^{41}$ El Decreto-ley n. ${ }^{\circ} 284$ realiza una modificación al mismo en cuanto adiciona una disposición especial al Decreto ley n. ${ }^{\circ} 278$ que será la cuarta: «Están exonerados de la obligación de afiliarse al régimen de Seguridad Social: la trabajadora de sesenta años o más y el trabajador de sesenta y cinco años o más. Los trabajadores que tengan cumplidas esas edades y de forma voluntaria permanezcan afiliados al régimen especial o lo hagan con posterioridad a la vigencia del presente decreto-ley recibirán los beneficios que les corresponden». También modifica las disposiciones primera y segunda del referido texto legal: «Primera. Durante el término de diez años, contados a partir del mes siguiente al de la fecha de entrada en vigor del presente decreto-ley, el trabajador que ingrese al régimen con menos de cincuenta años de edad, si es mujer, y cincuenta y cinco años de edad, si es hombre, puede abonar de forma voluntaria a la Seguridad Social, con efecto retroactivo, la contribución correspondiente por el tiempo que considere oportuno a partir de la fecha en que, debidamente autorizado, ejerce la actividad. Segunda. Durante el término de diez años, contados a partir del mes siguiente al de la fecha de entrada en vigor del presente decreto-ley, el trabajador que ingrese al régimen con menos de cincuenta años de edad, si es mujer, y cincuenta y cinco años de edad, si es hombre, puede abonar de forma voluntaria a la Seguridad Social, con efecto retroactivo, la contribución referida en los arts. 12 y 13 por el tiempo que considere oportuno a partir de la fecha en que, debidamente autorizado, ejerza la actividad».

42 Alejandra García Elizalde, «El sindicato, apoyo para el trabajador cuentapropista», Periódico Granma, La Habana, 23 de mayo de 2017. 
actividades más representativas se ubican las de transporte, la elaboración de alimentos y el arrendamiento de viviendas.

En paralelo a lo anterior, la ANPP aprobó, el 20 de diciembre de 2013, la nueva Ley no.116 «Código del Trabajo». Éste supone la modificación de 101 artículos, la inclusión de 28 nuevas normativas y la total reelaboración del Capítulo II, referente a las Organizaciones Sindicales, el artículo 2 acerca de los principios que rigen el derecho de trabajo y la modificación parcial de su Capítulo XV referente a las autoridades de Trabajo.

Por primera vez se desarrollan las relaciones laborales en el sector privado, en una sección de capítulo enteramente dedicado a ello (Sección primera, Capítulo VII), que regula las «Relaciones de trabajo entre personas naturales» y establecen los «derechos mínimos que debe garantizar el empleador».

Aunque se mantienen gran parte de las prácticas y técnicas de ordenación laboral existentes en el anterior Código ${ }^{43}$, el nuevo introduce fuertes elementos de flexibilidad laboral. El comunicado del secretariado nacional de la Central de Trabajadores de Cuba (CTC), de 13 de septiembre de 2010, establecía: «se modificará el actual tratamiento laboral y salarial (...) pues ya no será posible aplicar la fórmula de proteger o subsidiar salarialmente de forma indefinida a los trabajadores».

En este sentido, y para mencionar algunos ejemplos, el nuevo Código elimina la redacción del viejo según la cual «el contrato de trabajo por tiempo determinado debe expresar la fecha de su terminación, que no puede exceder de tres años», permitiendo que los contratos temporales por tiempo determinado no se encuentran sometidos a límite temporal máximo de duración, lo que dota de notable inseguridad jurídica a los trabajadores contratados bajo esta modalidad.

Además, se extiende la duración del periodo de prueba. De acuerdo con la antigua ley, éste no podía exceder de 30 días, en el actual Código del Trabajo este puede abarcar «entre treinta y hasta ciento ochenta días» (art. 32). Asimismo, los nuevos arts. 36, 37 y 38 utilizan el indeterminado concepto de «idoneidad demostrada» para posibilitar la terminación del contrato de trabajo por iniciativa del empleador.

Cambian también las condiciones para los llamados trabajadores disponibles. Se denomina así a aquellos que se amortizaba su plaza y se le brindaba la posibilidad de reubicarse en otra plaza. Hasta ahora solo se aplicaban procesos de disponibilidad cuando existían ofertas de reubicación de los trabajadores y la ley establecía que los trabajadores que eran despedidos recibían su salario básico completo hasta que fuesen colocados en otro Trabajo. El nuevo

${ }^{43}$ Sobre este, vid. Guillermo Ferriol, «El derecho laboral en Cuba. Fundamentos, actualidad y perspectivas», Alegatos, n. ${ }^{\circ} 72$ (2009): 29-66. 
Código del Trabajo prevé la figura de trabajadores disponibles que no puedan ser reubicados y reduce la cantidad de dinero a recibir. Ahora el subsidio del $100 \%$, será limitado únicamente a un mes, después del cual el trabajador recibirá un beneficio únicamente del $60 \%$ de su salario básico durante un mes para aquellos que han trabajado hasta 19 años, dos meses para aquellos que han trabajado entre 20 y 25 años, tres meses para aquellos que acumulan entre 26 y 30 años y un máximo de cinco meses para aquellos que han trabajado más de 30 años (art. 53).

En paralelo a las modificaciones en el Trabajo, se ha llevado a cabo también una reforma del sistema general de Seguridad social a través de la nueva Ley n. ${ }^{\circ} 195 / 2008$, de 27 de diciembre, desarrollada reglamentariamente mediante el Decreto n. ${ }^{\circ}$ 283/2009 del Consejo de Ministros, de 6 de abril.

El elemento más cuestionado de la nueva Ley ha sido el retraso de la edad de jubilación para tener derecho a la pensión, que pasa de 55 a 60 años para las mujeres y de 60 a 65 años para los Hombres (art. 22.I.a) ${ }^{44}$. Además, se modifican los requisitos requeridos para optar a una pensión por edad ${ }^{45}$ e introducen diversas modificaciones en el sistema de financiación de la Seguridad social, mediante aprobación de la nueva Ley n. ${ }^{\mathrm{o}}$ 113/2012 del sistema tributario y el Decreto n. ${ }^{\circ}$ 308/2012 del Consejo de Ministros que establece el Reglamento de las normas generales y procedimientos tributarios.

En 1962, se suprimió la obligación de cotizar para los trabajadores asalariados, estableciéndose el principio de contribución exclusiva del empleador. Durante todo este tiempo, los recursos para financiar el conjunto de Servicios y prestaciones ofrecidas gratuitamente por el Sistema Nacional de Salud y el régimen de asistencia social provenía de las cotizaciones de los empleadores

${ }^{44}$ Sobre la Ley de Seguridad social, vid.: «80 preguntas y respuestas sobre el antepro-

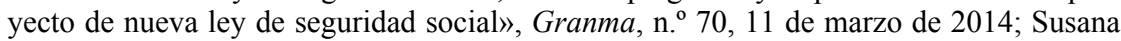
Lee, «En vigor Reglamento de la Ley de Seguridad Social», Granma, n. ${ }^{\circ}$ 129, 9 de mayo de 2009.

${ }^{45}$ Se aumenta el tiempo de servicios requerido de veinticinco a treinta años para optar por la pensión por edad en los trabajadores comprendidos en pensión ordinaria Categoría I; en tanto para los comprendidos en Categoría II, se eleva también la edad de jubilación en cinco años y se fija el tiempo de servicios en treinta años como mínimo, manteniendo la condición de haber laborado en trabajos comprendidos en esta categoría no menos de quince años anteriores a su solicitud, o el 75\% del tiempo de servicio requerido para tener derecho a la pensión, si en el momento de solicitarla no se encontraba desempeñando un cargo comprendido en esta categoría. Otro cambio importante es la forma de cálculo de la pensión. La Ley dispone que los cinco años naturales en los que el trabajador haya devengado sus mayores salarios, serán seleccionados dentro de los últimos quince y no diez como estipulaba la ley anterior [Jesús R. Mercader, Las últimas reformas laborales en Cuba (2009-2014) (Washington DC: Cuba Study Group, 2015), 6]. 
y de las transferencias del Presupuesto General del Estado. Teniendo en cuenta la incapacidad del anterior sistema para financiar la Seguridad Social, la nueva Ley tributaria de 2012 establece un impuesto sobre los ingresos personales de todos los trabajadores (arts. 16 y 17$)^{46}$.

\section{La sindicalización del trabajo por cuenta propia}

La Ley no. 116/2013 por la que se aprueba el nuevo Código del Trabajo, regula las organizaciones sindicales en su Capítulo II. La ampliación, desde 2010, del sector de trabajadores por cuenta propia ha ido acompañado de un plan de expansión de la sindicalización en el sector.

Las vías de sindicalización de estos trabajadores son diversas. La CTC tiene tres fuentes fundamentales de afiliación: los trabajadores estatales, los no estatales y los jubilados que bajo el principio de voluntariedad quieran sindicarse. Muchos de los trabajadores por cuenta propia mantienen, a la vez, un vínculo laboral con el sector estatal, por lo que acceden a las filas de la CTC desde su actividad estatal ${ }^{47}$. Respecto al resto, se estableció un plan mediante el que funcionarios de la CTC realizan visitas a cada negocio y conversan con cada trabajador, sin distinciones entre empleadores y empleado, para explicarles las ventajas de su afiliación. La CTC tiene creados 16 sindicatos que organizan a los trabajadores no estatales por las actividades económicas que realizan: gastronómicos, arrendatarios, artistas, usufructuarios, etc.

Según datos de la CTC, en mayo de 2017, el 81,9\% del total de trabajadores por cuenta propia del país estaban ya sindicalizados ${ }^{48}$. De acuerdo con la propia CTC, los objetivos de la sindicalización de este sector son básicamente tres: en primer lugar, facilitar las articulaciones entre el sector estatal y no estatal de la economía. Por ejemplo, con el apoyo del sindicato, el Ministerio del Turismo mantiene una atención directa con los arrendatarios de viviendas. Las entidades turísticas suelen entablar contratos directos con los trabajadores por cuenta propia y les permitan incorporarse a las ofertas de las agencias, además de viabilizar la relación con inmigración. En segundo lugar, apoyar el trabajo político-ideológico y evitar la proliferación de «ideologías neoliberales» en el naciente sector privado. Y, en tercer lugar, dar

${ }^{46}$ Con anterioridad a la nueva Ley, la Ley n. ${ }^{\circ}$ 73/1994 del sistema tributario, de 4 de agosto, ya había establecido un impuesto sobre los ingresos personales de los trabajadores asalariados en sus art. 18. Sin embargo, en la práctica, nunca se llegó a aplicar.

47 Alcides Francisco Antúnez, Carlos Justo Bruzón y Sudis María Velázquez, «Un análisis a partir de la constitución cubana sobre el ejercicio del autoempleo: incidencias en el nuevo relanzamiento del modelo económico del siglo XXI», Ibid.: 66.

48 Alejandra García Elizalde, «El sindicato, apoyo para el trabajador cuentapropista», Ibid. 
respuestas a las necesidades diversas de este sector, realizando, por ejemplo, encuentros periódicos con los secretarios generales de las secciones sindicales donde los trabajadores por cuenta propia plantean sus quejas y demandas.

\section{Atracción y ampliación de la inversión extranjera}

Con el objetivo de atraer y ampliar la inversión extranjera de la isla, en 2014 se aprobó la Ley n. ${ }^{\circ} 118$ de inversión extranjera, de 29 de marzo, que deroga la anterior de 1995. Esta ley introduce distintas novedades, entre ellas, establece que la inversión extranjera puede ser autorizada en todos los sectores, con excepción de los servicios de salud y educación a la población, $\mathrm{y}$ de las instituciones armadas, salvo en sus sistemas empresariales ${ }^{49}$.

Además, la Ley introduce la nueva figura de la «cartera de oportunidades», una especie de catálogo dirigido a los inversionistas extranjeros en el que se publican, cada año, las oportunidades de inversión en promoción y regula garantías para los inversionistas que antes no estaban recogidas, explícitamente, en la ley anterior ${ }^{50}$. A la vez, reconoce a las empresas mixtas, los inversionistas nacionales y los inversionistas extranjeros partes en contratos de asociación económica internacional, y las empresas de capital totalmente extranjero, un conjunto de beneficios en materia de exención fiscal ${ }^{51}$.

La Cartera de Oportunidades de Inversión Extranjera 2017-2018, contó con 456 proyectos, por un monto de capital ascendente a 10.700 millones de dólares. Se potenciaron los proyectos que generan encadenamientos productivos. Con relación a la versión anterior se incorporaron 156 proyectos, 29 de ellos en la Zona Especial de Desarrollo Mariel (ZEDM). Los proyectos prioritarios se concentraron en los sectores de Turismo (152), Agroalimentario (104 de ellos, 10 ubicados en la ZEDM), Azucarero (7), Industria (33 de ellos, 17 ubicados en la ZEDM), Farmacéutico y Biotecnológico (15 de ellos,

${ }^{49}$ Sobre ello, vid. O.E. Pérez Villanueva, La ruta necesaria del cambio económico, Ciencias Sociales, La Habana, 2013. La ruta necesaria del cambio económico (La Habana: Ed. Ciencias Sociales, 2013); O.E. Pérez Villanueva, «La inversión extranjera directa en Cuba: necesidad de su relanzamiento», Economía y desarrollo, Vol. 152-2 (2014): 37-52.

${ }^{50}$ Entre ellas, el Estado cubano garantiza que los beneficios concedidos a los inversionistas extranjeros y a sus inversiones se mantienen durante todo el período por el que hayan sido otorgados. También les garantiza la libre transferencia al exterior de sus dividendos y beneficios y la opción de venta en cualquier momento de su parte en la asociación.

${ }^{51}$ En concreto, es el Capítulo XII de la Ley n. ${ }^{\circ} 118$ de 2014, sobre el régimen especial de tributación el que atribuye incentivos fiscales para las empresas mixtas y asociaciones económicas internacionales, puesto que aunque aparecen impuestos regulados por la nueva Ley n. ${ }^{\circ} 113$ de 2012, del Sistema tributario, se eximen temporalmente y se reducen de manera significativa los tipos impositivos en muchos casos. 
13 ubicados en la ZEDM), Energías renovables (13), Construcción (14 de ellos, 5 ubicados en la ZEDM) ${ }^{52}$.

Todo ello, ha hecho aumentar, especialmente el número de empresas mixtas, durante los últimos años. La Administración cubana no detalla la identidad de los inversores extranjeros para protegerlos de actuaciones de Estados Unidos y, por ello, los datos disponibles son orientativos.

Según datos del Gobierno cubano de octubre de 2018, más del 50\% de los proyectos de inversión en Cuba provienen de países de la UE. Los sectores donde se concentra la inversión extranjera son la industria básica (energía, minería y cemento), el turismo, la industria ligera, la agricultura, la industria alimentaria (bebidas) y tabaco.

España es el principal inversor en una amplia gama de sectores tales como el turismo, industrias varias, servicios financieros, suministro de aguas, cemento, etc. Canadá ha sido tradicionalmente otro gran inversor en turismo, energía y níquel. Los inversores de los demás países juegan un papel poco relevante, salvo China, Brasil (en los sectores del níquel, tabaco y la gestión de un ingenio azucarero, operado por la empresa brasileña Odebrecht) y Venezuela (en la producción de software, exploración geológica, producción de insumos agrícolas, servicios de actividades agrícolas, desarrollo de flotas marítimas y reciclaje de chatarras. Así como en el sector del petróleo. Destaca la terminación de la refinería de petróleo de Cienfuegos, sin acabar desde la época soviética $)^{53}$.

\section{Cambios en la propiedad agraria y reforma de la Ley de vivienda}

En materia de propiedad agraria, una de las novedades introducidas en este periodo, a través del Decreto-Ley n. ${ }^{\circ}$ 259/2008, emitido por el Consejo de Estado, fue la entrega en usufructo a personas naturales o jurídicas de tierras ociosas para su producción agropecuaria ${ }^{54}$. El objetivo de esta medida fue la concesión de derechos a los campesinos para producir en mejores condiciones laborales y de sustento básico, así como mejorar la satisfacción de necesidades de alimentación de la población en general por el aumento de la producción alimentaria, lo que implica una disminución de los precios en el mercado, además de una mayor variedad y calidad.

52 Vid. Cuba. Cartera de oportunidades de inversión extranjera, 2017-2018: file://C:/Users/USER/Downloads/Cartera\%20de\%20Oportunidades\%20de\%20Inversin\%20Extranjera\%202017-2018.pdf

${ }_{53}$ Vid. http://www.exteriores.gob.es/Documents/FichasPais/CUBA_FICHA\%20 PAIS.pdf

${ }^{54}$ Desarrollado por el Decreto n. ${ }^{\circ} 282 / 2008$. «Reglamento para la implementación de la entrega de tierras ociosas en usufructo». 
El límite máximo a entregar a personas naturales sin tierras es de 13.42 hectáreas. En el caso de quienes posean tierras, en propiedad o usufructo, podrán incrementarlas hasta completar 40.26 hectáreas (art. 6). El periodo del usufructo es de hasta diez años y podrá ser prorrogado sucesivamente por términos de hasta diez años (art. 2). El Decreto obliga al usufructuario a trabajar personalmente la tierra concedida, así como la posibilidad de construir una vivienda e instalaciones de trabajo para el aprovechamiento de las labores allí realizadas.

Las personas jurídicas autorizadas para la entrega de tierra son granjas estatales, UBPC, cooperativas de producción agropecuaria, cooperativas de créditos y servicios, entidades estatales no agropecuarias y otras instituciones que quisieran destinar las tierras para el autoabastecimiento de sus trabajadores, además de otras que se autoricen excepcionalmente (art. 11). A éstas, se les otorga la tierra por un periodo de veinticinco años prorrogable a un período igual (art. 2) . $^{55}$.

Esta regulación ha sufrido diversas modificaciones. En 2012, este Decreto-Ley fue sustituido por el Decreto-Ley n. ${ }^{\circ} 300 / 2012$, de entrega de tierras estatales en usufructo. En 2013, el último de 2012 volvió a ser modificado por el Decreto-Ley n. ${ }^{\circ} 311 / 2013$ modificativo del anterior.

Las reformas al primer Decreto-Ley van en el sentido de ampliar la cota máxima de tierra a entregar ${ }^{56}$. Asimismo, teniendo en cuenta que la mayoría de tierras han sido entregadas a campesinos individuales ${ }^{57}$, para evitar procesos individualistas de producción y favorecer la asociación colectiva, desde 2012, se establece que el usufructuario deberá estar vinculado, mediante una relación contractual, a una granja estatal con personalidad jurídica, una unidad básica de producción cooperativa (UBPC), o una cooperativa de producción agropecuaria (CPA); ubicadas en una proximidad de hasta cinco kilómetros.

${ }^{55}$ En julio de 2009 se habían realizado 110 mil solicitudes de entrega de tierras ociosas en usufructo y se aprobaron cerca de 82 mil, abarcando unas 690 mil hectáreas que implicaban el 39 \% del área de tierras ociosas del país («Entrevista a Orlando Lugo Fonte, Presidente de la Asociación Nacional de Agricultores Pequeños (ANAP)», Periódico Trabajadores, 22 de junio 2009).

56 Se mantiene la solicitud inicial en un área de 13,42 hectáreas, pero más tarde esta puede extenderse hasta 67,10 hectáreas. Anteriormente se aprobaban hasta 40,26 hectáreas.

${ }^{57}$ Hasta 2012 se habían otorgado 1.523 .000 hectáreas. Habían sido procesadas 197.000 solicitudes, de las cuales 174.271 ya habían sido aprobadas. Entre el total de solicitudes, 2.700 corresponden a personas jurídicas y el resto a personas naturales. De estas últimas, entre el $9 \%$ y $10 \%$ son mujeres, $23 \%$ tiene experiencia en la agricultura, lo cual arroja $77 \%$ sin dominio de la actividad. Más de $35 \%$ de los usufructuarios tenían entre 20 y 35 años («Nuevas regulaciones sobre la entrega de tierras en usufructo», Opciones. Semanario económico y Financiero de Cuba, 26 de octubre de 2012). 
Otro cambio importante en la isla ha sido el de la autorización de la compraventa de viviendas, mediante el Decreto-Ley 288/2011 del Consejo de Estado, de 28 de octubre, modificativo de la Ley General de Vivienda n. ${ }^{\circ} 65 / 1988$, acompañado de seis resoluciones complementarias para aplicar la ley ${ }^{58}$.

Hasta este momento, estaban permitidas las permutas o intercambios, pero no la compraventa de viviendas. La nueva reforma autoriza la compraventa de viviendas por parte de ciudadanos y extranjeros residentes permanentes en la isla y permite a los compradores y vendedores fijar libremente el precio. La permuta subsiste, pero ahora es legal el pago de una compensación que antes se hacía de forma ilegal. Con el fin de evitar la concentración de propiedades, el Decreto-Ley limita la posesión de propiedades a dos, una residencia permanente y otra de veraneo o descanso ${ }^{59}$.

\section{LA CONSTITUCIÓN DE 2019 Y LOS NUEVOS REGIMENES DE PROPIEDAD EMERGENTES}

Del 20 al 22 de julio de 2018, la Asamblea Nacional del Poder Popular (ANPP) de Cuba inició el trámite de discusión de un anteproyecto de nueva Constitución cubana elaborado por un grupo de trabajo del Buró Político del Partido Comunista de Cuba (PCC) creado el 13 de mayo de 2013 y una comisión parlamentaria creada el 2 de junio de 2018 para este objetivo. El nuevo texto sometido, de acuerdo con el art. 72 del Reglamento de la ANPP, a un proceso de discusión popular entre la ciudadanía y, finalmente, a ratificación mediante referendo popular en febrero de 2019, introduce nuevas e importantes novedades en materia de propiedad.

El art. 18 de la Constitución señala que la forma principal de propiedad en el país es la «propiedad socialista de todo el pueblo sobre los medios fundamentales de producción». Esto se complementa con el art. 27 que afirma que «la empresa estatal socialista es el sujeto principal de la economía nacional». Sin embargo, la necesidad de adelgazamiento del ineficaz sector estatal obliga a desarrollar otros tipos de propiedad y/o gestión de los medios de producción y Servicios.

${ }_{58}$ Resolución 85/11 del Banco Central de Cuba; Resoluciones 342 y 343/11 del Instituto Nacional de la Vivienda; Resolución 351/11 del ministerio de Finanzas y Precios; y, Resolución 270/11 del Ministerio de Justicia.

${ }_{59}$ Damien Cave, «Cuba to allow buying and selling of property, with few restrictions», The New York Times, 4 de novembre de 2011; Carmelo Mesa-Lago, «Las reformas de Raúl Castro y el congreso del Partido Comunista de Cuba: avances, obstáculos y resultados», Documentos CIDOB América Latina, n. 35 (2011): 8. 
En este sentido, el art. 22 de la Constitución reconoce las siguientes formas de propiedad: la socialista de todo el pueblo; la cooperativa; la mixta; de las organizaciones políticas, de masas y sociales; la privada; y, la personal.

En esta enumeración hay dos novedades, la primera es que se reconoce la propiedad cooperativa, en general. Las pocas referencias que la Constitución de 1976 hacía a la propiedad cooperativa se referían sólo a las cooperativas agropecuarias. Y la segunda, es la referencia a la propiedad privada. La Constitución anterior reconocía sólo la personal.

Con ello, la Constitución abre la puerta a dos posibles vías de sustitución del amplio sector estatal en el socialismo cubano: la vía de la propiedad cooperativa o de la propiedad privada, las cuales se convierten en las nuevas formas de propiedad emergentes.

\section{La propiedad cooperativa}

El anteproyecto de Constitución presentado en julio de 2018 por la Asamblea Nacional y sometido a proceso de discusión popular entre la ciudadanía, reconocía, en su art. 21, las formas de propiedad citadas (la socialista de todo el pueblo; la cooperativa; la mixta; de las organizaciones políticas, de masas y sociales; la privada; y, la personal) y seguidamente, incluía un último párrafo de este artículo que señalaba que el Estado «estimula aquellas formas de propiedad de carácter más social». Con lo cual se entendía, que se fomentaría la propiedad cooperativa por encima de la privada.

Después del proceso de consulta entre la ciudadanía, de la sistematización de las propuestas hechas en los debates ciudadanos y de su incorporación en el texto final de la Constitución que se aprueba mediante referéndum, la referencia del último párrafo al estímulo estatal de las formas de propiedad de carácter más social, desaparece. El texto final de la Constitución establece, simplemente, «Todas las formas de propiedad sobre los medios de producción interactúan en similares condiciones».

Tradicionalmente había existido, en la Cuba socialista, una desconfianza hacia la propiedad cooperativa, motivada por los escritos de Ernesto Ché Guevara. En sus notas críticas sobre la economía política de la URSS, escritas entre 1965 y $1966^{60}$, el Ché lleva a cabo una fuerte crítica contra las cooperativas agrícolas en la URSS, conocidas como koljós, las cuales en su criterio estaban introduciendo una superestructura capitalista dentro la sociedad socialista. Éste sostenía que las cooperativas no constituyen una forma socialista de propiedad pues imponen una superestructura con relaciones de

${ }^{60}$ Ernesto Guevara, Apuntes críticos de la economía política (La Habana: Ciencias Sociales, 2006). 
propiedad y palancas económicas capitalistas ${ }^{61}$. Ello ha supuesto siempre un obstáculo al desarrollo de esta forma de propiedad en la isla.

Hasta 2012, solo se reconocían en Cuba cooperativas de tipo agropecuario (Cooperativas de Créditos y Servicios, Cooperativas de Producción Agropecuaria y UBPC). La cooperativa se entendía, además, como una forma de organizar un patrimonio del Estado cedido en usufructo a la cooperativa o a sus socios y cuyas decisiones estaban supeditadas al ministerio del que dependieran. A partir de 2012 y siguiendo los lineamientos aprobados por el VI Congreso del PCC de 2011 (Lineamientos 2, 25, 26, 27, 28 y 29), el Decreto ley 305/2012 del Consejo de Estado «De las cooperativas no agropecuarias» y el Decreto ley 306/2012 del Consejo de Estado «Del régimen especial de seguridad social de los socios de las cooperativas no agropecuarias» abren la posibilidad para la constitución de cooperativas no agropecuarias en la isla ${ }^{62}$. Ahora la cooperativa pasa a entenderse como una persona jurídica de derecho privado sin relación con los organismos de Estado y que puede pueden fijar libremente los precios de sus productos (art. 25 DL 306 y 66.2 D 309). Asimismo, reconoce también las llamadas cooperativas de segundo grado como forma de federación de distintas cooperativas para organizar actividades complementarias entre ellas.

Además, junto al reconocimiento de las cooperativas no agropecuarias, el Estado fomenta su creación mediante la adopción de distintas medidas en beneficio de esta forma de propiedad. Así, el art. 51 del Decreto n. ${ }^{\circ}$ 309/2012 que establece el Reglamento de las cooperativas no agropecuarias de primer grado $^{63}$, exonera del pago del alquiler, hasta un año y por una sola vez, a

${ }^{61}$ Sobre ello, vid. Helen Yaffe, «El Ché Guevara: Las cooperativas y la economía política de la transición al socialismo», en Cooperativas y socialismo. Una mirada desde Cuba, comp. por Camila Piñeiro (La Habana: Ed. Caminos, 2011), 132-166.

${ }_{62}$ Junto a estas normas y en relación con elles se dicta también el Decreto ley 309/2012 del Consejo de Ministros «Reglamento de las cooperativas no agropecuarias de primer grado», la Resolución 570/2012 del Ministerio de Economía y Planificación y la Resolución 427/2012 del Ministerio de Finanzas y Precios. A raíz de la aprobación de esta legislación, a primeros de julio 2013 ya habían comenzado a funcionar las primeras 124 cooperativas asociadas a actividades del transporte, la construcción, la recogida de materias primes y los mercados agropecuarios. Entre estas cooperativas la mayoría se desprenden del sector estatal (112) por no resultar esa forma de gestión eficiente, y el resto, surgen del trabajo por cuenta propia, además de estas, un nuevo grupo de setenta y una ya ha sido aprobado y van a empezar a funcionar (Ana María Puyo, «la nueva normativa cubana de cooperativas no agropecuarias», Revista Vasca de Economía Social, n. ${ }^{\circ} 11$ (2014): 179.

${ }^{63}$ El Decreto-Ley número 305, de 15 de noviembre de 2012, «De las Cooperativas no Agropecuarias», en su Disposición Final Sexta dispone que el Consejo de Ministros, una vez que entre en vigor el referido Decreto-Ley, emite el Reglamento para las Cooperativas de primer grado. 
aquellas Cooperativas que asuman en el transcurso del primer año de su existencia la reparación de las instalaciones estatales arrendadas.

En materia fiscal, el Estado también les otorga un conjunto de beneficios. El apartado segundo de la Resolución del Ministerio de Finanzas y Precios 427/2012, «exonera a las cooperativas no agropecuarias del Impuesto sobre Ventas por la comercialización a la población de productos agropecuarios». El apartado séptimo establece, para estas cooperativas, un conjunto de deducciones al impuesto sobre utilidades ${ }^{64}$. La Ley no. 113/2012, «del Sistema Tributario», les exime del pago de las obligaciones tributarias por los primeros 3 meses iniciales de operaciones por los conceptos siguientes: impuesto sobre Utilidades, impuesto sobre las Ventas, impuesto sobre los Servicios, impuesto por la Utilización de la Fuerza de Trabajo.

Asimismo, se establece que las cooperativas no agropecuarias que tienen la licencia de exportación están exentas del pago del Impuesto sobre las Ventas por todas las operaciones de exportación (art. 153 b. Ley no. 113). O que se eximen del pago del Impuesto por la Utilización de la Fuerza de Trabajo a aquellas que posean de 1 a 5 trabajadores contratados ${ }^{65}$.

Como fija el Decreto-Ley 306, sobre el régimen especial de seguridad social de los socios de las cooperativas no agropecuarias, ellas deberán realizar contribuciones a la seguridad social según un régimen especial. Los miembros de cooperativas cuentan con todas las prestaciones de la seguridad social del régimen general (protección por enfermedad, accidentes profesionales o no, maternidad, invalidez total y a su familia en caso de muerte), y a diferencia de los Trabajadores por cuenta propia que contribuyen con una base de un $25 \%$, la base para los cooperativistas es de un $20 \%{ }^{66}$.

${ }^{64}$ Apartado séptimo: «Para el cálculo del Impuesto sobre Utilidades, las cooperativas no agropecuarias, al total de los ingresos obtenidos en el año fiscal, además de los conceptos que se descuentan conforme a lo establecido en el artículo 108 de la nueva Ley n. ${ }^{\circ} 113$ «Del Sistema Tributario» se deducirán los siguientes conceptos: a) El arrendamiento de los bienes muebles e inmuebles a entidades debidamente autorizadas para ello, que les sean exoneradas o bonificadas, cuando asuman reparaciones en los locales estatales que arrienden, las que deben ser justificadas documentalmente; b) una retribución por socio, consistente en el salario medio de la provincia, o en su caso, en el municipio especial Isla de la Juventud, donde esté establecida u opere la cooperativa; y c) los montos destinados a la creación de las reservas para cubrir contingencias. Los gastos asociados a la actividad serán contabilizados en su totalidad y no se exigirá justificación del cuarenta por ciento $(40 \%)$ de estos»».

${ }^{65}$ Contraloría General de la República de Cuba. Funcionamiento de las Cooperativas no agropecuarias [folleto], La Habana, 2016: 68. Disponible en: http://www.contraloria. gob.cu/documentos/eventos/Programa\%20Cooperativas\%20no\%20agropecuarias.pdf

${ }^{66}$ Camila Piñeiro, «Las cooperativas no agropecuarias en La Habana. Diagnóstico preliminar», en Economía Cubana: Transformaciones y Desafios, comp. Por Camila Piñeiro et.al. (La Habana: Ciencias Sociales, 2014), 6. 
Respecto al financiamiento de estas cooperativas, se creó un fondo fideicomiso del Presupuesto del Estado que será gestionado por los bancos a partir de las normas emitidas por el Banco Central de Cuba, que será destinado en forma de créditos blandos a aquellas cooperativas que por sus condiciones iniciales no sean sujeto de crédito. Como establece el DL 305, este fondo será a partir de una reserva del presupuesto del Estado que se le va a dar al sistema bancario para que otorgue créditos, fundamentalmente, para capital inicial. Las cooperativas podrán además solicitar créditos a los bancos comerciales, en condiciones similares a una empresa estatal ${ }^{67}$. Hasta enero de 2014 el $73 \%$ de las cooperativas aprobadas en los dos primeros grupos habían solicitado créditos ${ }^{68}$.

Todos estos elementos han favorecido que, desde 2012 en adelante, hayan empezado a crearse cooperativas de trabajo no agropecuarias en la isla. En mayo de 2014, ya existían un total de 498 Cooperativas no agropecuarias en distintas actividades económicas, de las cuales 384 fueron de origen estatal y 114 no estatal.

Actividades y número de cooperativas autorizadas (mayo 2014)

\begin{tabular}{|r|r|r|r|}
\cline { 2 - 4 } \multicolumn{1}{c|}{ Actividad } & N. $^{\mathbf{0}}$ & \% \\
\hline 1 & Gastronomía & 213 & 42,9 \\
\hline 2 & Comercio minorista de productos agropecuarios & 101 & 20,3 \\
\hline 3 & Construcción y producción de materiales de construcción & 68 & 13,7 \\
\hline 4 & Servicios personales y técnicos & 32 & 6,4 \\
\hline 5 & Comercialización de aves & 17 & 3,4 \\
\hline 6 & Recuperación de desechos & 15 & 3,0 \\
\hline 7 & Transporte de carga y servicios al transporte & 11 & 2,2 \\
\hline 8 & $\begin{array}{l}\text { Muebles, cerámica, confecciones textiles, calzado, talabarte- } \\
\text { ría, plásticos }\end{array}$ & 11 & 2,2 \\
\hline 9 & Transporte de pasajeros & 6 & 1,2 \\
\hline 10 & Servicios contables & 6 & 1,2 \\
\hline 11 & Producción y servicios decorativos & 5 & 1,0 \\
\hline 12 & Servicios de energía & 5 & 1,0 \\
\hline
\end{tabular}

67 Ibid.

68 Ibid. 


\begin{tabular}{l|r|r|c|}
\cline { 2 - 4 } \multicolumn{1}{c|}{ Actividad } & N. $^{\mathbf{0}}$ & \multicolumn{1}{c|}{$\%$} \\
\hline 13 & Producción de alimentos y bebidas & 3 & 0,6 \\
\hline 14 & Servicios técnicos de mantenimiento y reparación de equipos & 3 & 0,6 \\
\hline 15 & Impresiones gráficas, decoración e interiorismo & 1 & 0,2 \\
\hline 16 & Comercialización mayorista de productos agropecuarios 1 0.2 & 1 & 0,2 \\
\hline & Total & 498 & \\
\hline
\end{tabular}

Fuente: Centro de Investigaciones de Desarrollo Local (CIDEL), La Habana, Mayo 2014 (Tomado de: Camila Piñeiro, «Las cooperativas no agropecuarias en La Habana. Diagnóstico preliminar», ibid.: 11).

En el año 2015 se produjo un modesto incremento de 22 nuevas cooperativas, de las cuales 19 fueron en La Habana, dos en Artemisa y una en Cienfuegos ${ }^{69}$.

A pesar de las ventajas señaladas, diversos autores, en el interior de la isla, señalan la necesidad, todavía, de superar muchas deficiencias si lo que se quiere es facilitar este tipo de propiedad para que pueda convertirse en una auténtica alternativa al adelgazamiento del sector estatal. Entre ellas, estos autores $^{70}$, señalan problemas referidos a un proceso legal de constitución demasiado largo, complicado, burocratizado y supeditado a la voluntad administrativa. Un régimen económico confuso. Un régimen de disciplina social y solución de conflictos poco eficaz. O, la inexistencia de una organización que represente los intereses de las nuevas cooperativas ante el Estado, que podría conformarse como consejos de cooperativas desde el nivel municipal al nivel nacional y que, entre otras tareas, podría cumplir funciones

${ }^{69}$ Silvia Odriozola Guitart y Ady Regla Palma Arnaud, «Cooperativas no agropecuarias en el sector de la construcción en La Habana: un análisis de su gestión», Economía y Desarrollo, n. ${ }^{\circ} 159$ (1) (2018): 89.

${ }^{70}$ Maelia Esther Silveira Pérez, «Las cooperativas a la luz de los nuevos cambios económicos en Cuba. Actualidad y perspectivas de futuro», Cubalex, Revista electrónica de estudios jurídicos, . $^{\circ} 4$ (2010); Camila Piñeiro, «¿Y las cooperativas, cuando? Potencialidades de las cooperativas para la actualización del modelo económico cubano», Palabra Nueva, n. 211 (2011): 55-56; Jesús Cruz y Camila Piñeiro, «Una introducción a las cooperativas», en Cooperativas y Socialismo: Una mirada desde Cuba, comp. Por Camila Piñeiro (La Habana: Editorial Caminos, 2011), 31-54; Camila Piñeiro, "Ahora que sí van las cooperativas, vamos a hacerlo bien. Roles de las cooperativas en el nuevo modelo económico cubano», Revista Caminos, 5 de febrero de 2013; Vid. También. Roberto Muñoz, Grizel Donéstevez y Jaime García, Desarrollo y cooperativismo: desafios al modelo cubano de transición al socialismo (La Habana: Editorial Caminos, 2014). 
similares a las que hoy realiza la Asociación Nacional de Agricultores Pequeños (ANAP) en relación a las cooperativas agropecuarias.

\section{Propiedad privada y privatizaciones}

La propiedad privada constituye el otro sector emergente en la isla. En paralelo a lo anterior, la nueva Constitución reconoce ahora el papel del mercado $^{71}$ en la economía y abre la posibilidad para la privatización de la propiedad y/o gestión de un amplio número de bienes y servicios.

La Constitución anterior de 1976, en su art. 15, listaba el conjunto de los bienes que conformaban la propiedad social y afirmaba ser inalienables ${ }^{72}$, salvo casos excepcionales, donde debían cumplirse dos requisitos: que dicha transmisión se destinara a los fines de desarrollo del país, y que no afectara los fundamentos del Estado, es decir, la «existencia de una economía basada en la propiedad socialista de todo el pueblo».

La nueva Constitución introduce cambios importantes en este artículo, que ahora pasa a ser el 23. En concreto, elimina del listado de bienes inalienables, imprescriptibles e inembargables: los centrales azucareros, las fábricas, los medios fundamentales de transporte, empresas, bancos, instalaciones y bienes nacionalizados y expropiados, así como granjas del pueblo, fábricas e instalaciones económicas, sociales, culturales y deportivas construidas. Asimismo, éstos quedan también fuera de los dos requisitos consignados para la transmisión de derechos, es decir, se puede autorizar que otros actores los usen, disfruten y gestionen, aunque ello afecte los fundamentos del Estado, y aunque no contribuya al desarrollo del país ${ }^{73}$.

Respecto a «otros bienes» incluidos en la propiedad socialista de todo el pueblo (infraestructuras de interés general, principales industrias e instalaciones

${ }^{71}$ El art. 18 de la Constitución incluye la regulación del mercado dentro del marco de la planificación económica.

72 Estos bienes listados en la Constitución son: «las tierras que no pertenecen a los agricultores pequeños o a cooperativas integradas por los mismos; sobre el subsuelo, las minas, los recursos marítimos naturales y vivos dentro de la zona de su soberanía, los bosques, las aguas, las vías de comunicación; sobre los centrales azucareros, las fábricas, los medios fundamentales de transporte, y cuantas empresas, bancos, instalaciones y bienes han sido nacionalizados y expropiados a los imperialistas, latifundistas y burgueses, así como sobre las granjas del pueblo, fábricas e instalaciones económicas, sociales, culturales y deportivas construidas, fomentadas o adquiridas por el Estado y las que en el futuro construya, fomente o adquiera» (art. 15).

${ }^{73}$ Sobre ello, vid. Luís Emilio Aybar Toledo, «El proyecto de Constitución abre puertas a la privatización de la propiedad social», La Tizza Cuba, 10 de septiembre de 2018, disponible en: https://medium.com/la-tiza/el-proyecto-de-constituci\%C3\%B3n-abrepuertas-a-la-privatizaci\%C3\%B3n-de-la-propiedad-social-d6da49c0e2b3. 
económicas y sociales, así como otros de carácter estratégico para el desarrollo económico y social del país), el art. 24 los mantiene como inalienables, aunque en el último párrafo establece que respecto a su gestión se actuara conforme lo establecido por la ley, abriendo la puerta a la gestión privada de esta parte de la propiedad estatal. Además, aunque el art. 30 fija la obligación del Estado de regular la concentración de la propiedad en personas no estatales con el fin de «preservar los límites compatibles con los valores socialistas de equidad y justicia social», no se dice nada sobre la concentración de la gestión de bienes y Servicios de propiedad estatal en una misma empresa, lo que no deja de ser otra forma de concentración.

A la vez, el art. 18 de la anterior Constitución donde se dice que «El comercio exterior es función exclusiva del Estado», se elimina en la nueva, no especificándose el régimen bajo el que éste funcionará.

\section{CONCLUSIONES}

De acuerdo con lo expuesto hasta aquí, hemos visto como la aprobación de la Ley Fundamental de 1959 implicó una modificación del art. 24 de la Constitución de 1940, en cuanto que ahora se abría la posibilidad de expropiación sin previa indemnización. Ello permitió abrir, entre 1959 y 1968, una etapa de nacionalización y confiscación de tierras y bienes que suponen un cambio radical de la estructura de propiedad en la isla, configurándose la propiedad estatal como casi único modelo de propiedad y reduciéndose al mínimo las formas de trabajo por cuenta propia.

No será hasta la década de los 90 , con el desplome del campo socialista y la adopción de reformas para hacer frente a la fuerte crisis económica, que se empiezan a introducir cambios en las formas de propiedad, apareciendo ahora la propiedad de las empresas mixtas, sociedades y asociaciones económicas y produciéndose un fraccionamiento de la gran propiedad agraria estatal, y una importante ampliación del ámbito del trabajo por cuenta propia, aunque éste es visto todavía con recelo. Es a partir de 2011, ante la necesidad de adelgazar un ineficaz sector estatal, que el trabajo por cuenta propia pasa a ser visto como una alternativa real de trabajo para una amplia masa de trabajadores provenientes del sector estatal, y empieza a desarrollarse una amplia normativa respecto a éste.

A la vez, desde 2007, momento en que Fidel castro abandona la dirección política del país, empiezan también a adoptarse un conjunto de modificaciones respecto a la propiedad agraria, la vivienda, etc. que constituyen el preludio de la actual Constitución de 2019. Este texto amplía las formas de propiedad, estableciendo dos nuevas formas de propiedad emergentes y carentes, hasta el momento, de reconocimiento constitucional: la de las cooperativas no agropecuarias y la propiedad privada. 


\section{BIBLIOGRAFÍA}

Álvarez TABio, F. Comentarios a la Constitución Socialista (La Habana: Editorial Pueblo y Educación, 1989), 83.

Antúnez, A.F., Justo Bruzón, C. y Velázquez, S.M. «Un análisis a partir de la constitución cubana sobre el ejercicio del autoempleo: incidencias en el nuevo relanzamiento del modelo económico del siglo XXI», Foro, vol. 16, n. ${ }^{\circ} 1$ (2013): 75.

AYBAR Toledo, L.E. «El proyecto de Constitución abre puertas a la privatización de la propiedad social», La Tizza Cuba, 10 de septiembre de 2018, disponible en: https://medium.com/la-tiza/el-proyecto-de-constituci $\% \mathrm{C} 3 \% \mathrm{~B} 3$ n-abre-puertas-ala-privatizaci\%C3\%B3n-de-la-propiedad-social-d6da49c0e2b3.

Burgos, M. «Análisis Crítico Constitucional de los Cambios Socio-jurídicos en la Cuba Actual», Revista Direito \& Práxis, n. ${ }^{\circ} 4$ (2017): 3179.

CARranza, J., GutiérRez, L. y MonReAl, P. Cuba: la reestructuración económica. Una propuesta para el debate (La Habana: Ed Ciencias Sociales, 1995).

CAVE, D. «Cuba to allow buying and selling of property, with few restrictions», The New York Times, 4 de novembre de 2011.

Contraloría General de la República de Cuba. Funcionamiento de las Cooperativas no agropecuarias [folleto], La Habana, 2016: 68. Disponible en: http:// www.contraloria.gob.cu/documentos/eventos/Programa\%20Cooperativas $\% 20$ no\%20agropecuarias.pdf

CRUZ, J. y PIÑEIRO, C. «Una introducción a las cooperativas», en Cooperativas y Socialismo: Una mirada desde Cuba, comp. Por Camila Piñeiro (La Habana: Editorial Caminos, 2011), 31-54.

— «Cuba. La economía al cierre de 1997», en Revista Cuba Socialista, n. ${ }^{\circ} 9$ (1998): 46 Ver Boletín de Información Económica, IPS, no 30 (1994).

— «Entrevista a Orlando Lugo Fonte, Presidente de la Asociación Nacional de Agricultores Pequeños (ANAP)», Periódico Trabajadores, 22 de junio 2009).

ESPINA, M. «Reestratificación y desigualdad», en Mayra Espina et.al. Heterogeneidad social en la Cuba actual (La Habana: Centro de Estudios de Salud y Bienestar Humano, 2004), 19.

— «Reforma económica y reestratificación de la estructura socio-clasista cubana», Revista Academia, nº1-2 (2001): 27.

Fernández Bulté, J. «Problemas y desafíos de Cuba contemporánea: el sistema político y el sistema jurídico», ponencia presentada en el Taller Problemas y desafíos para Cuba contemporánea (Notre Dame: Instituto Kellog para Estudios Internacionales, 1998).

— «Tras las pistas de la Revolución en cuarenta años de Derecho», Revista Temas, no 16-17 (1999): 105.

FERRIOL, G. «El derecho laboral en Cuba. Fundamentos, actualidad y perspectivas», Alegatos, n. 72 (2009): 29-66.

FIgUeROA, V. «El nuevo modelo agrario en Cuba bajo los marcos de la reforma económica», en Desarrollo rural y participación (La Habana: Ediciones de la Universidad de La Habana, 1996).

GARCÍA ElizALDE, A. «El sindicato, apoyo para el trabajador cuentapropista», Periódico Granma, La Habana, 23 de mayo de 2017. 
García Henríquez, F.E., Martínez Lorenzo, Y. y Martínez Barreiro, J. Compendio de disposiciones legales sobre nacionalización y confiscación (La Habana: Ministerio de Justicia, 2004), 48-147.

GARCÍA VALDÉS, C. «La economía cubana de los años 90: transformaciones en la economía socialista», en Economía: Análisis, propuestas, alternativas, comp. Por Carlos García Valdés et.al. (La Habana: Ed. Ciencias Sociales, 1998), 40.

GuevarA, E. Apuntes críticos de la economía política (La Habana: Ciencias Sociales, 2006).

LAGE, C. «Discurso en la inauguración de la XII Feria Internacional de La Habana», en Periódico Granma, 1 de noviembre de 1994.

MARQUETTI, H. La economía del dólar: balance y perspectivas, revista TEMAS, n. ${ }^{\circ} 11$ (1997).

MERCADER, J.R. Las últimas reformas laborales en Cuba (2009-2014) (Washington DC: Cuba Study Group, 2015), 6.

Mesa-Lago, C. «Las reformas de Raúl Castro y el congreso del Partido Comunista de Cuba: avances, obstáculos y resultados», Documentos CIDOB América Lati$n a$, . $^{\circ} 35$ (2011): 8 .

MIRANDA, O. «Las nacionalizaciones cubanas», en Temas de Derecho constitucional cubano, comp. por Marta Prieto y Lissette Pérez (La Habana: Ed. Félix Varela, 2000), 83.

Muñoz, R., Donéstevez, G. y GARcíA, J. Desarrollo y cooperativismo: desafios al modelo cubano de transición al socialismo (La Habana: Editorial Caminos, 2014).

Noguera, A. Derecho y Hegemonía. Un estudio socio-jurídico de la Cuba actual (Buenos Aires: Ediciones Cooperativas, 2007), 117.

OPCIONES. «Nuevas regulaciones sobre la entrega de tierras en usufructo», Opciones. Semanario económico y Financiero de Cuba, 26 de octubre de 2012.

NuÑEZ, L. «Más allá del cuentapropismo en Cuba», Revista Temas, n. ${ }^{\circ} 11$ (1997).

Odriozola Guitart, S. y Palma Arnaud, A.R. "Cooperativas no agropecuarias en el sector de la construcción en La Habana: un análisis de su gestión», Economía y Desarrollo, n. ${ }^{\circ} 159$ (1) (2018): 89.

PererA, M. La subjetividad en grupos de la capital [Mecanuscrito inédito] (La Habana: Fondos del Centro de Investigaciones Psicológicas y Sociológicas, 2002), 7-8.

PÉREZ N. y ECHEVARRÍA, D. «Participación y producción agraria en Cuba: las UBPC», Revista Temas, n. ${ }^{\circ} 11$ (1997): 71.

PÉREZ, Y. Fundamentos jurídicos para la armonización de intereses públicos y privados en sede de alojamiento turístico en Cuba [tesis doctoral], Universidad de La Habana, 2014, Disponible en: file://C:/Users/USER/Desktop/documentos $\% 20$ bajados/Fundamentos $\% 20$ juridicos $\% 20$ para $\% 201 a \% 20$ a $\% 20-\% 20$ Perez\%20Martinez,\%20Yuri.pdf

PÉrez Villanueva, O.E. La ruta necesaria del cambio económico (La Habana: Ed. Ciencias Sociales, 2013).

— «La inversión extranjera directa en Cuba: necesidad de su relanzamiento», Economía y desarrollo, Vol. 152-2 (2014): 37-52.

PIÑEIRO, C. «Las cooperativas no agropecuarias en La Habana. Diagnóstico preliminar», en Economía Cubana: Transformaciones y Desafios, comp. Por Camila Piñeiro et.al. (La Habana: Ciencias Sociales, 2014), 6. 
— « ¿Y las cooperativas, cuándo? Potencialidades de las cooperativas para la actualización del modelo económico cubano», Palabra Nueva, n. ${ }^{\circ} 211$ (2011): 55-56.

— «Ahora que sí van las cooperativas, vamos a hacerlo bien. Roles de las cooperativas en el nuevo modelo económico cubano», Revista Caminos, 5 de febrero de 2013.

— «Plan para la economía nacional de 1964», Revista Cuba Socialista, n. 3 (1964).

PrIETO, M. «Reflexiones en torno al carácter normativo de la Constitución», en Temas de Derecho constitucional cubano, comp. por Marta Prieto y Lissette Pérez (La Habana: Ed. Félix Varela, 2000), 33.

- El orden constitucional cubano. Realidades y perspectivas [manuscrito inédito], Marzo 2005.

PuYo, A.M. «la nueva normativa cubana de cooperativas no agropecuarias», Revista Vasca de Economía Social, n. ${ }^{\circ} 11$ (2014): 179.

SILVEIRA PÉREZ, M.E. «Las cooperativas a la luz de los nuevos cambios económicos en Cuba. Actualidad y perspectivas de futuro», Cubalex, Revista electrónica de estudios jurídicos, $\mathrm{n}^{\mathrm{o}} 4$ (2010).

TrianA, J. «La transformación económica en el socialismo», Academia. Revista del Colegio de Ciencias Sociales y Humanidades de la Universidad de La Habana, n. ${ }^{\circ} 1$ (2001): 23).

YAFFe, H. «El Ché Guevara: Las cooperativas y la economía política de la transición al socialismo», en Cooperativas y socialismo. Una mirada desde Cuba, comp. por Camila Piñeiro (La Habana: Ed. Caminos, 2011), 132-166. 


\title{
REGIMEN DE PROPIEDAD Y TRABAJO POR CUENTA PROPIA EN CUBA: DE 1959 A LA NUEVA CONSTITUCIÓN DE 2019
}

\author{
Property regime and work for own account in Cuba: \\ from 1959 to the new constitution of 2019
}

\author{
Albert Noguera Fernández \\ Universitat de València \\ albert.noguera@uv.es
}

http://dx.doi.org/10.18543/ed-67(1)-2019pp315-350

\section{Copyright}

Estudios de Deusto es una revista de acceso abierto, lo que significa que es de libre acceso en su in tegridad. Se permite su lectura, la búsqueda, descarga, distribución y reutilización legal en cualquier tipo de soporte sólo para fines no comerciales, sin la previa autorización del editor o el autor, siempre que la obra original sea debidamente citada y cualquier cambio en el original esté claramente indicado

Estudios de Deusto is an Open Access journal which means that it is free for full access, reading, search, download, distribution, and lawful reuse in any medium only for non-commercial purposes, without prior permission from the Publisher or the author; provided the original work is properly cited and any changes to the original are clearly indicated. 